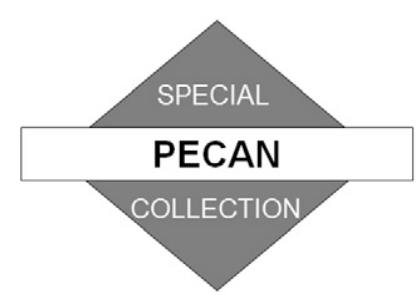

\title{
Analysis of Back-Building Convection in Simulations with a Strong Low-Level Stable Layer
}

\author{
STACEY M. HITCHCOCK \\ Department of Atmospheric Science, Colorado State University, Fort Collins, Colorado, and ARC Centre of Excellence for \\ Climate Extremes and School of Earth Sciences, University of Melbourne, Melbourne, Victoria, Australia \\ RUSS S. SCHUMACHER \\ Department of Atmospheric Science, Colorado State University, Fort Collins, Colorado
}

(Manuscript received 25 July 2019, in final form 30 June 2020)

\begin{abstract}
In a mesoscale convective system (MCS), convection that redevelops over (i.e., back-builds), and/or repeatedly passes over (i.e., trains) a region for an extended period of time can contribute to extreme rainfall and flash flooding. Past studies have indicated that both mesoscale ascent and lifting of the inflow layer by a cold pool or bore are important when this back-building/training convection is displaced from the leading line [sometimes called rearward off-boundary development (ROD)]. However, Plains Elevated Convection At Night (PECAN) field campaign observations suggest that the stability of the nocturnal boundary layer is highly variable and some MCSs with ROD have only a weak surface cold pool. Numerical simulations presented in this study suggest that in an environment with strong boundary layer stability, ROD can be supported by mechanisms other than those mentioned above. Simulations were initialized using a sounding from ahead of a PECAN MCS with a strong stable layer and ROD, and the three-dimensional simulation produced an MCS similar to that observed despite the homogeneous initial conditions. Some of the findings presented herein challenge existing understanding of nocturnal MCSs, and especially how downdrafts interact with a stable boundary layer. Notably, downdrafts can reach the surface, and different regions of the MCS may have different propagation mechanisms and different relevant inflow layers. Unlike previous studies of ROD, parcel lifting may be supported by an intrusion (an elevated layer of downdraft air) modified by the three-dimensional vertical wind shear.
\end{abstract}

\section{Introduction}

Heavy rainfall can serve both as a valuable source of water, and a dangerous contributor to flash flooding around the world. Mesoscale convective systems (MCSs) are one of the major producers of heavy rainfall (Maddox et al. 1979; Maddox 1980). More specifically, since total precipitation is directly related to the rate and duration of rainfall (Doswell et al. 1996), MCSs that have convective elements that "train," or back-build over the same location are particularly conducive to extreme precipitation (e.g., Chappell 1986; Schumacher and Johnson 2005). Training occurs where cells move parallel to the orientation of the convective line, resulting in

Corresponding author: Stacey M. Hitchcock, stacey.hitchcock@ unimelb.edu.au repeated motion over the same location. In backbuilding convection, new cells repeatedly regenerate upstream, while mature cells decay downstream resulting in quasi-stationary behavior of the convective region (Schumacher and Johnson 2005).

Analysis of these heavy rainfall-producing MCS environments have led to several different methods of classification, but two distinct categories consistently emerge for events over the central Great Plains. In synoptic-type events, a strong midtropospheric trough and slow moving surface front lead to strong forcing for ascent in a region with southerly flow and associated moisture transport. During the warm season, isentropic ascent of warm, moist air transported by the nocturnal low-level jet (LLJ) can lift an air to saturation on the cool side of a stationary or warm front (Schumacher 2017, and citations 
therein). In both cases, cloud layer winds can lead to cell motion parallel to the boundary and training/ back-building.

Corfidi et al. (1996) developed a technique to forecast the instances of back-building or quasi-stationary convection using the mean cloud layer wind and the (negative of) the LLJ. This was expanded to forecast forward propagation in Corfidi (2003). In a conceptual model in Corfidi (2003), the gust front is thought to elongate in the direction of the mean wind, and quasistationary convection is thought to form along the portion of the outflow boundary parallel to the mean wind. Schumacher and Johnson $(2008,2009)$ and Schumacher (2009) explore the development and maintenance of back-building convection in MCSs in the absence of a surface front (Type 2 MCS; Fritsch and Forbes 2001). They found that back-building can be maintained by a latent-heating-forced gravity wave oriented approximately perpendicular to the inflow winds over the same layer. Liu and Moncrieff (2017) found that in very moist environments with unidirectional vertical wind shear along the mei-yu front where cold pools were weak, shear parallel back-building was supported by a combination of two gravity wave modes acting in concert. Other instances of back-building or training convection can form offset from a leading convective line. A "bow and arrow" MCS (Keene and Schumacher 2013) has both a forward-propagating leading line (the bow) and a region of convection that develops nearly perpendicular to the leading line some distance offset from the leading southwest outflow boundary. This "arrow" portion of the convection is sometimes referred to as rearward off-boundary development (ROD; Peters and Schumacher 2014), which more generally refers to convection that develops offset from and behind a leading convective line (regardless of whether it bows or not). In these cases, back-building or training convection offset from a leading convective line is thought to be supported by a combination of external forcing for ascent due to the interaction of the low-level jet and the quasi-stationary surface front and lifting through gradual ascent over the leading edge of a cold pool boundary associated with the forward propagating convective line (Keene and Schumacher 2013; Peters and Schumacher 2016).

Several recent studies motivated by the Plains Elevated Convection At Night (PECAN) field campaign (Geerts et al. 2017) have begun to investigate a multitude of MCS-bore-environment interactions (e.g., Parsons et al. 2019; Grasmick et al. 2018; Haghi et al. 2019; Chasteen et al. 2019; Loveless et al. 2019). Thus far, outside of individual case studies, work on training convection has not distinguished between daytime and nighttime cases and composite environments have had only a weak stable layer (e.g., Figure 9 in Peters and Schumacher 2015b). During PECAN, observed stability varied substantially from case to case and even within individual cases, but some cases had very strong stable layers (Hitchcock et al. 2019). Some studies have posed that the relative strength of the low-level stable layer may impact the ability of a convective storm's downdrafts to reach the surface (Raymond and Rotunno 1989; Trier and Parsons 1993; Haertel et al. 2001; Parker 2008; Marsham et al. 2010). Those MCSs can be maintained by processes other than cold pools, which has been explored previously through observational (e.g., Marsham et al. 2010), theoretical (e.g., Moncrieff 1992), and modeling approaches (e.g., Schmidt and Cotton 1990; Schumacher 2009). However, despite observed stability, several other studies have found that some MCSs may continue to draw inflow from the near-surface layer, even after significant cooling has occurred (Davis et al. 2004; Parker 2008; French and Parker 2008; Billings and Parker 2012; Parker et al. 2020). These studies suggest that nocturnal convection may actually not be as decoupled from the boundary layer as previously thought. In an environment with a stable boundary layer, characteristics of the stable layer, wind shear, and convective downdrafts influence the character of the MCS outflow (e.g., cold pool, bore, gravity wave). What would happen in the case of Peters and Schumacher (2016) if the low-level stability was so strong that a surface-based cold pool was not produced? Are there still cases where it is possible to have ROD in the absence of a low-level cold pool, supported by another mechanism?

In this study, we will address these questions through analysis of a series of 2D and 3D numerical simulations initialized with a sounding from 25 June 2015, the PECAN MCS case with the strongest observed preconvective stable layer (Hitchcock et al. 2019). Following the explanation of the simulation set up, the results begin with an overview of the simulated MCS, with an emphasis on paths and sources of parcels that enter updrafts in the region of ROD. To understand the processes that might support convection in this region in the absence of previously studied mechanisms, and in order to better understand what actually happens when a downdraft impinges on a strong low-level stable layer in the presence of vertical wind shear, three 2D simulations (each with different vertical wind profiles) were run. Analysis of these simulations is organized around the construction of an idealized conceptual model that can be used to explain several of the major questions posed by the 3D simulations. This is followed by a discussion that 
TABLE 1. Model setup.

\begin{tabular}{|c|c|}
\hline Setting & \\
\hline Initiation & $\begin{array}{l}\text { Four } 1-\mathrm{K} \theta^{\prime} \text { at } 1.4 \mathrm{~km}, \\
\text { hrad }=10 \mathrm{~km}, \operatorname{vrad}=1.4 \mathrm{~km} \\
\text { spaced } 20 \mathrm{~km} \text { apart }\end{array}$ \\
\hline Domain & $1608 \times 1608 \times 72$ \\
\hline$d x, d z$ & $\begin{array}{l}250 \mathrm{~m} \text {, stretched below } 3.5 \mathrm{~km} \text { : } \\
100-250 \mathrm{~m}\end{array}$ \\
\hline$d t$ & $2 \mathrm{~s}$ \\
\hline Advection & Fifth-order positive definite \\
\hline Subgrid turbulence & TKE \\
\hline Pressure solver & $\begin{array}{l}\text { Klemp-Wilhelmson time- } \\
\text { splitting, vertically implicit }\end{array}$ \\
\hline Microphysics & Morrison \\
\hline $\mathrm{LBCs}$ & $\begin{array}{l}\text { Open radiative (Durran and } \\
\text { Klemp 1983) }\end{array}$ \\
\hline Model top & $16.5 \mathrm{~km}$ with Rayleigh damping \\
\hline Model bottom & Free slip \\
\hline Other & No Coriolis \\
\hline
\end{tabular}

considers limitations, previously unconsidered additional explanations for some of the unique features in the simulation, and comments on the elevated nature of MCSs in this environment.

\section{Methods}

Cloud Model 1 (CM1; Bryan and Fritsch 2002), version 19.1 , was run on a $1608 \times 1608 \times 72$ gridpoint domain with $250-\mathrm{m}$ horizontal grid spacing, a stretched vertical grid from 100 to $250 \mathrm{~m}$ below $3.5 \mathrm{~km}$ and a $16.5-\mathrm{km}$ model top. The domain was set to translate east at $9 \mathrm{~m} \mathrm{~s}^{-1}$ and north at $8 \mathrm{~m} \mathrm{~s}^{-1}$. Fifth-order positive definite advection, the Klemp-Wilhelmson time-splitting, vertically implicit pressure solver (Klemp and Wilhelmson 1978), and a 2-s time step were used. Open radiative lateral boundary conditions were used to allow fast moving gravity waves created during initiation to escape the domain. Rayleigh damping was applied near the model top, and a free slip condition was applied at the surface. This simulation uses Morrison microphysics with hail (Morrison et al. 2005), and no Coriolis force. The Deardorff (1980) scheme was used for subgrid-scale turbulence. A summary of model setup details can be found in Table 1.

The sounding used to initialize the environment was taken by a mobile team at 0444 UTC 25 June 2015 during PECAN (Fig. 1; Ziegler et al. 2016). The sounding was launched $\sim 15 \mathrm{~min}$ before convection passed over the launch location (Fig. 2). On that night, remnants from an earlier cold pool contributed to a particularly deep stable layer; $\theta$ increased $9.5 \mathrm{~K}$ over the lowest $707 \mathrm{~m}$. The observed convection this day had both a forward-propagating leading line and a region of ROD (Fig. 2).
Smoothing was applied using a Barnes analysis [see Parker (2014) for more detail on this method] to all fields in order to reduce noise. Additional minor adjustments were necessary to reduce the gradient of wind with height near the peak of the LLJ. A combination of large gradients in wind and near-neutral stability can lead to low Richardson numbers and Kelvin-Helmholtz instabilities $(\mathrm{Ri}<0.25)$. While these instabilities often exist in the real atmosphere, they are not desirable in initial conditions of a horizontally homogeneous simulation without surface fluxes (Coffer and Parker 2015), and led to rapid overturning. Unlike soundings often used in these types of simulations, the sounding used was sufficiently moist through a very deep layer so no moisture modifications (e.g., Peters and Schumacher 2015b), or forced large-scale lifting (Crook and Moncrieff 1988; Loftus et al. 2008; Schumacher 2009) was needed to initiate convection. Instead, four $1-\mathrm{K}$ warm bubbles with a $10-\mathrm{km}$ horizontal and $1-\mathrm{km}$ vertical radius and spaced $20 \mathrm{~km}$ apart were used.

Passive tracers were placed in the lowest $500 \mathrm{~m}$ at the start of the simulation in order to help identify stable air lifted by updrafts. Passive tracers were also placed in the layer below $1 \mathrm{~km}$ in order to help identify convective outflow air with the idea that the replacement of the near-surface air mass by convective outflow would lead to the removal of passive tracer. Further justification for this decision will be discussed in the presentation of 2D heat sink simulations used to understand downdraftstable-layer interactions. Additionally, forward parcel trajectories were initialized in the southern $3 / 4$ of the domain below $4 \mathrm{~km}$ with a vertical spacing of $250 \mathrm{~m}$ and a horizontal spacing of $2 \mathrm{~km}$. In this case, the top of the stable layer was located above $700 \mathrm{~m}$, so tracers and parcels placed below $500 \mathrm{~m}$ should adequately represent the near-surface environment since any parcel from below $500 \mathrm{~m}$ would most certainly be in associated with very stable air in this case (also, $\sim 500 \mathrm{~m}$ has been used to represent the near surface in other frequently referenced studies, such as Parker 2008).

\section{Results}

Despite the strong low-level stable layer and horizontally homogeneous initial conditions, a mature, multimodal MCS was able to develop in this environment. The simulated MCS has a forward propagating leading line and two different regions of back-building convection offset from the leading southwest gust front boundary (Fig. 3). While the study was motivated by the observed 24-25 June MCS, the idealized simulation is not intended to be an exact replica of the observed MCS. The simulated MCS organization and elevated cool perturbations 


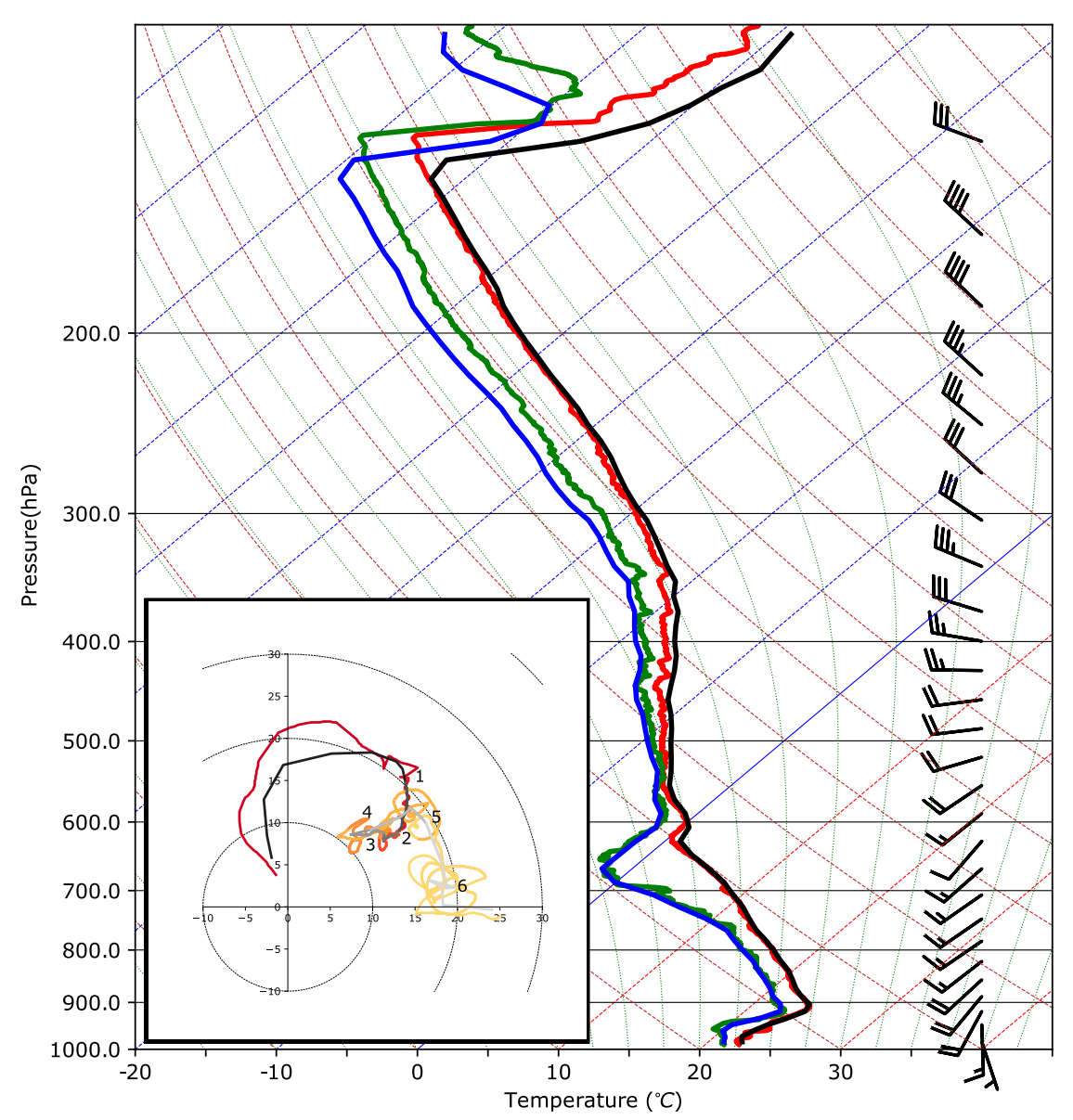

FIG. 1. Skew $T-\log p$ of the original 0444 UTC 25 Jun 2015 PECAN sounding ( $T$ in red, $T_{d}$ in green), and the sounding used to initialize the homogeneous environment used in simulations ( $T$ in black, $T_{d}$ in blue, wind barbs in black). Shades of red on the inset hodograph are original sounding winds, and grayscale lines are input sounding winds.

are similar to those of the 24-25 June MCS (described below), but other aspects are more difficult to connect to observations for reasons that will be discussed more in section 3a. The analysis presented here will aim to 1) explore the interaction between convective outflow and this environment and 2) understand what supports ROD in the simulated MCS given the absence of a surface cold pool off the southwestern flank. A few other interesting features of this simulation will also be discussed.

\section{a. Simulation overview}

Precipitation begins about 20-30 min after the start of the simulation, radar reflectivity fields from the individual cells begin to merge together after about an hour, and the simulated convection begins to display more MCS-like characteristics between 2 and $2.5 \mathrm{~h}$ as it develops a bowing leading line, multiple instances of ROD, and begins a more east-south-eastward propagation (Fig. 3a). In one instance (located between $y=100-150 \mathrm{~km}$ in Fig. 3d), ROD refers to a line of strong convective cells oriented NW to SE, apparently connected to the leading line (Fig. 3; ROD1), but offset from the leading gust front boundary (distinguishable by a wind shift, increase in pressure, and narrow band of 500-m updrafts in (Fig. 4). A second region of ROD (ROD2) with heavy precipitation develops even further offset from the leading gust front boundary (around $y=225 \mathrm{~km}$ in Fig. 3d), disconnected from the leading line, and is of particular interest in this study for reasons described below. The leading line continues to move toward the east throughout the duration of the simulation, while new convection develops in the wake region nearly perpendicular to, and offset from, the leading line.

One of perhaps the most striking things about this simulation is that a more traditional cold pool is only formed in some regions of heaviest precipitation several hours into the simulation (Fig. 3, -0.5 -K blue contours). Instead, there is a positive density potential temperature 

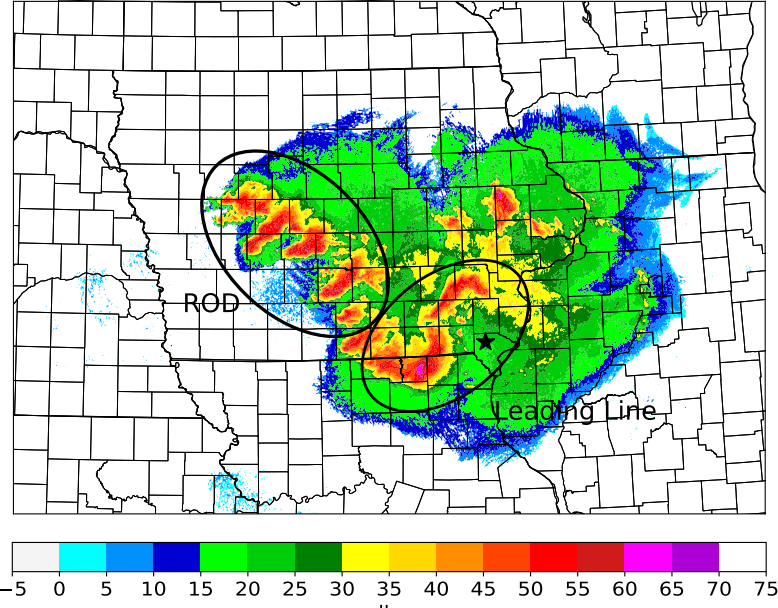

FIG. 2. Radar reflectivity at 0415 UTC 25 Jun 2015 and location of the sounding in Fig. 1 (black star). Approximate leading line and ROD regions identified by ellipses.

perturbation $\theta_{\rho}^{\prime}$ at the surface over large proportions of the domain, even once the MCS has matured, 3-4 h into the simulation (Fig. 4a). Rather, the greatest cooling observed in this simulation occurs in an elevated layer (Fig. 4b). The largest decrease in $\theta_{\rho}$ is observed between 650 and $800 \mathrm{~m}$ above the ground, which agrees well with the observations of the postconvective environment on the day of the sounding used to initialize the simulation (Table 4 in Hitchcock et al. 2019). This elevated cooling is even more clear in vertical cross sections through three different locations (identified by lines in Fig. 4a), but the structure of $\theta_{\rho}^{\prime}$ and its relationship to convective updrafts is different in each region (Figs. 5a,c,e). Note that throughout this paper, all cross sections are averages over a width of $3 \mathrm{~km}(1.5 \mathrm{~km}$ to either side of the lines like those shown in (Fig. 4a).

\section{MCS UPDRAFT MAINTENANCE}

In cross sections through the portion of convection with a strong eastward component of the leading line $\left(\mathrm{A}-\mathrm{A}^{\prime}\right)$, the largest elevated $\theta_{\rho}$ deficits were greater than $5 \mathrm{~K}$, yet were only $0.25 \mathrm{~K}$ at the surface at the same location (Fig. 4a). The coincident pressure increase, sustained positive wind perturbations, and $\theta_{\rho}$ decrease around $x=290 \mathrm{~km}$ may seem suggestive of a surface cold pool, but the weak decrease in $\theta_{\rho}$ was short lived $\sim 15 \mathrm{~km}$, and followed by surface warming $(x=225$ $275 \mathrm{~km}$ ). Furthermore, passive tracer placed below $1 \mathrm{~km}$ (gold lines) indicates that air "flows through" the initial wavelike perturbation around $x=290$, but is then removed immediately below and in a region extending behind the leading line downdrafts (Fig. 5b). A possible alternative explanation is a "right side up" dominated intrusion, or a density current that moves through an elevated layer, like that described in Ungarish (2005, 2009), preceded by a bore. ${ }^{1}$ The "right side up" dominated intrusion is made possible by much stronger environmental stratification below the intrusion than above it. The combination of the bore and intrusion resembles an "elevated cold pool" in the $\theta_{\rho}^{\prime}$, but the passive tracer suggests that air flows "through" the leading wavelike perturbation. A more intensive discussion and support for this will be provided in section $3 \mathrm{c}$. The warm perturbations at the surface will also be linked to the intrusion in section $3 \mathrm{c}$, and other considerations are discussed in section 4 a.

Cross sections through $\mathrm{B}-\mathrm{B}^{\prime}$ pass through a region of ROD that is still linked to the leading line. Here, it is clear that updrafts $(x=200 \mathrm{~km})$ are well removed from the gust front boundary associated with the leading line $(x=220 \mathrm{~km}$, Fig. 4c). In this case, the sustained increase in the height of the 298-306-K isentropes coincident with an increase in pressure and surface wind shift is evidence of a bore (Fig. 4d). Note that here, air flows through the cool perturbations in an elevated layer, but is removed in a shallow layer near the surface some distance ahead of the leading line $(x=210)$, unlike in the previous cross section (Figs. $5 \mathrm{c}, \mathrm{d}$ ). However, the bore alone appears to be unable to lift parcels to their LFCs. Much like in Blake et al. (2017), parcels entering this region of ROD are lifted gradually by the bore (via Peters and Schumacher's 2016 method), but are only lifted to their LFCs some distance behind its leading edge (See their Fig. 18). Chasteen et al. (2019) mentions similar behavior in their case analysis. Since this instance of ROD is relatively consistent with Peters and Schumacher (2016), Blake et al. (2017), and Chasteen et al. (2019), we will focus more attention on the ROD that is further removed from the leading line (ROD2), where new updrafts form in a region with essentially no surface cold pool (Figs. 4a,d).

\section{b. Rearward off-boundary development}

To better understand what parcels experience before they enter updrafts in the ROD2 region, 1880000 passive parcels were placed in the southern $3 / 4$ of the domain (south of $y=300 \mathrm{~km}$ ). Parcels were initiated every $250 \mathrm{~m}$ between $z=50 \mathrm{~m}$ and $z=4.05 \mathrm{~km}$. A sample of parcels that reached a vertical velocity of $5 \mathrm{~m} \mathrm{~s}^{-1}$ in a small region of the ROD convection (identified by the box in Fig. 6j) at $4 \mathrm{~h}$ are assumed to have made it into

\footnotetext{
${ }^{1}$ Observations associated with bores are described in Rottman and Simpson (1989) and organized in great detail alongside other types of observable boundaries in Haghi et al. (2017).
} 

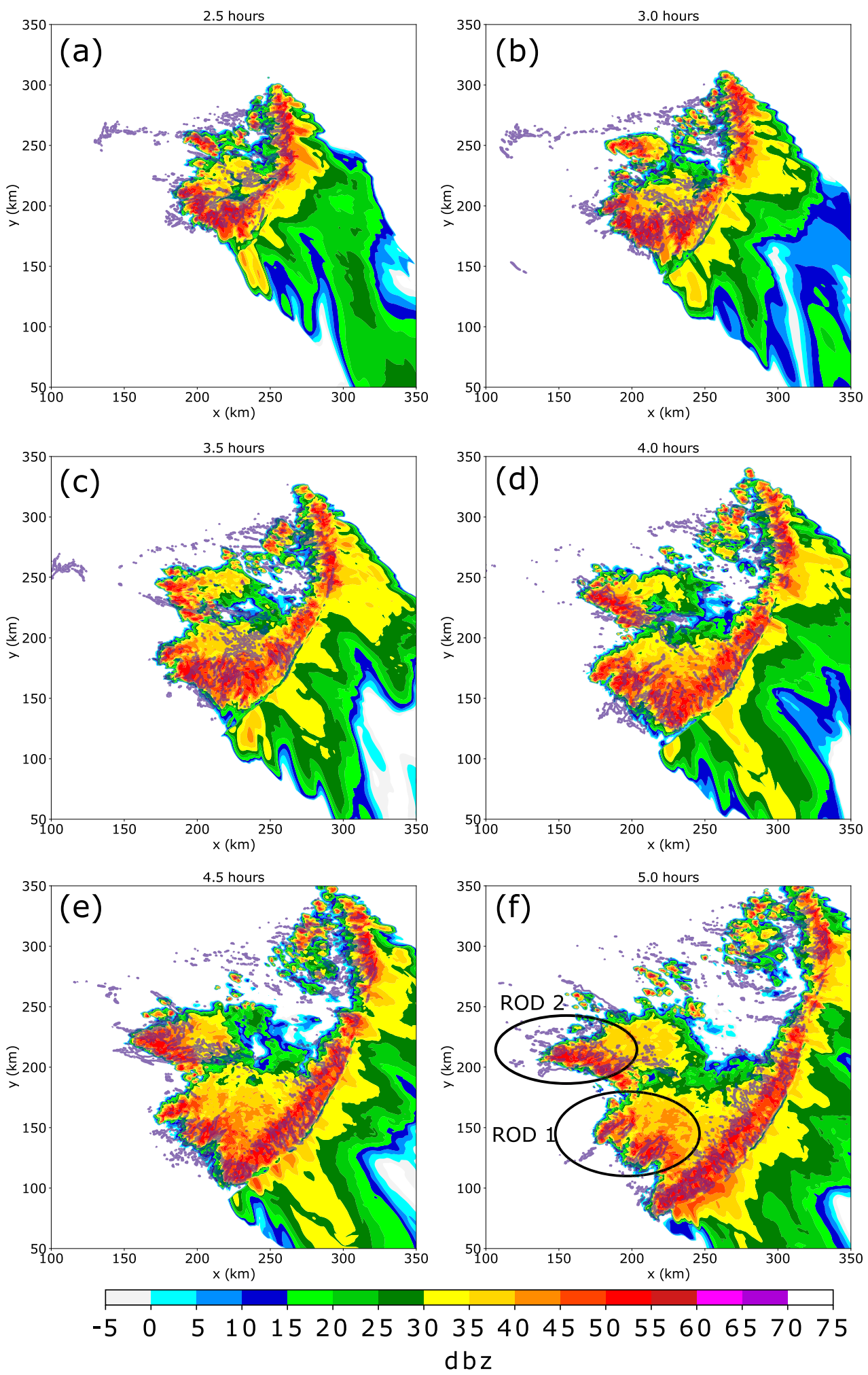

FIG. 3. Simulated reflectivity at the lowest model level every 30 min from 2.5 to $5 \mathrm{~h}$. Semitransparent blue contours indicate $-0.5-\mathrm{K}$ surface $\theta^{\prime}$. 

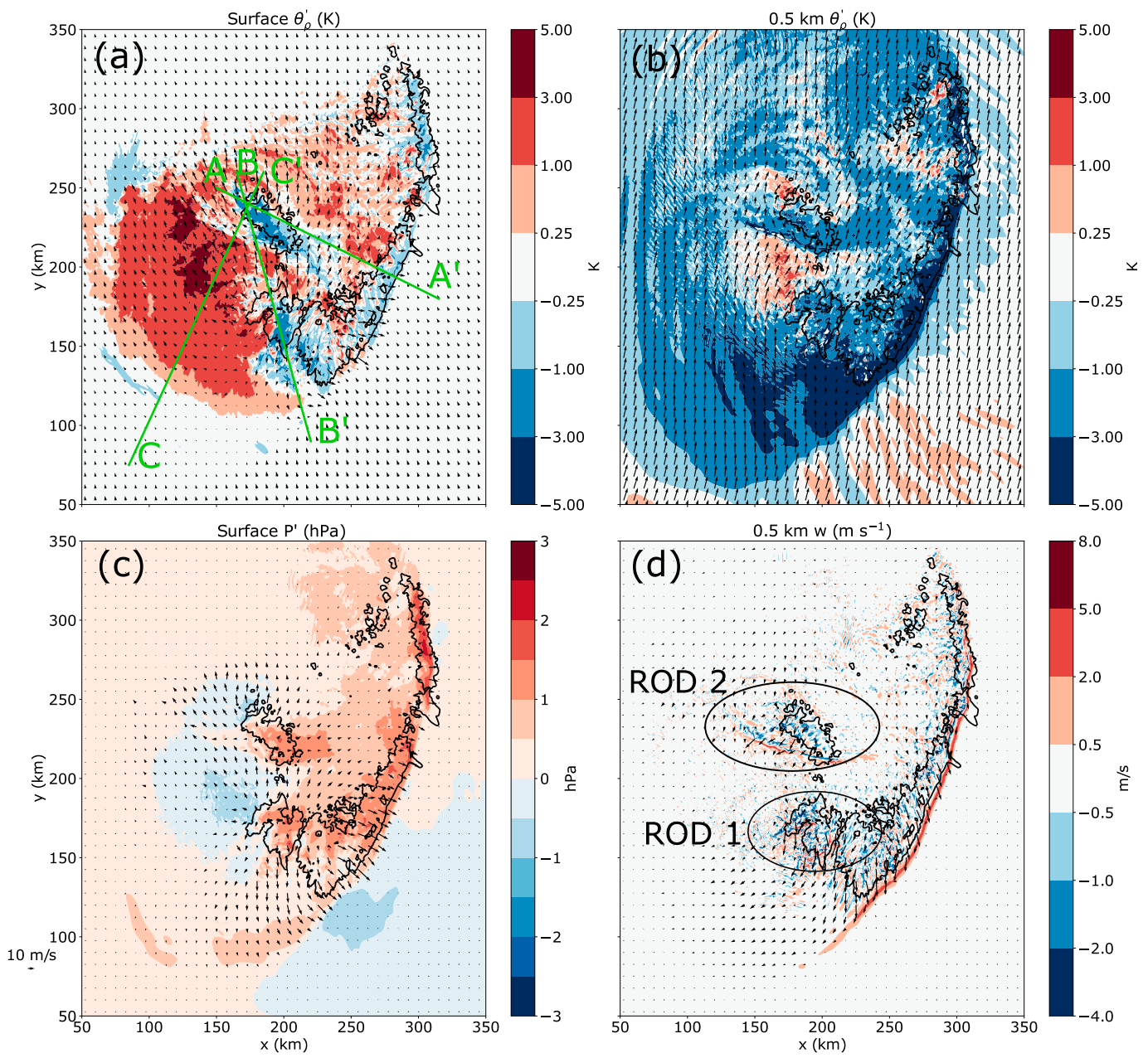

FIG. 4. Output at $t=4 \mathrm{~h}$ of (a) surface $\theta_{\rho}^{\prime}$ (shaded), 40-dBZ reflectivity at lowest model level (black contours), and Earth-relative surface wind vectors. (b) As in (a), but for wind vectors and $\theta_{\rho}^{\prime}$ (shaded) at $0.5 \mathrm{~km}$. (c) $P^{\prime}$ (shaded), 40-dBZ reflectivity at lowest model level (black contours), and surface wind perturbation vectors. (d) As in (c), but for $w$ in shaded contours.

ROD updrafts at this time. Figure 6 shows the path of these parcels in 1-h chunks (from $t-45$ through $t+15 \mathrm{~min}$ ) beginning at $2.5 \mathrm{~h}$. All three cross sections discussed in the previous section also intersect updrafts in the region of ROD. However, cross section $\mathrm{C}-\mathrm{C}^{\prime}$ most closely follows the trajectory of parcels that enter these updrafts, and is displayed in Fig. 6, which will be the focus of much of the ROD discussion that follows.

The majority of parcels that reach ROD updrafts in this region come primarily from southwest of the MCS, and become increasingly westerly with height. Parcels encounter the shallow bore that extends from the southwest flank of the convection (discussed above) and curve along their trajectories in toward the ROD updrafts. The vast majority of parcels come from the $800 \mathrm{~m}-$ $2 \mathrm{~km}$ layer; Parcels below $800 \mathrm{~m}$ that do reach updrafts in this region interact with the leading line first, and parcels above $2 \mathrm{~km}$ experience several meters to over $1 \mathrm{~km}$ of descent over the time before they reach the updraft region (Figs. 7b,c). Unlike like the parcels discussed in Peters and Schumacher (2015a), the $800 \mathrm{~m}-$ $2 \mathrm{~km}$ parcels experience more wavelike oscillations at the leading edge of the gust front boundary. They then ascend over a relatively short period of time, to varying heights, reaching a peak height around $x=145 \mathrm{~km}$ (Fig. 6e), just before $3 \mathrm{~h}$ (Fig. 7a). The $800 \mathrm{~m}-2 \mathrm{~km}$ parcels then descend, some returning nearly to their starting heights, before being lifted into ROD updrafts. So instead of a gradual ascent lifting parcels to their level of free convection behind the southwest gust front boundary, the ascent is much more dramatic, and occurs closer to the convection.

In the preconvective environment, a layer of parcels around $1 \mathrm{~km}$ needed to be lifted just over $300 \mathrm{~m}$ to reach 

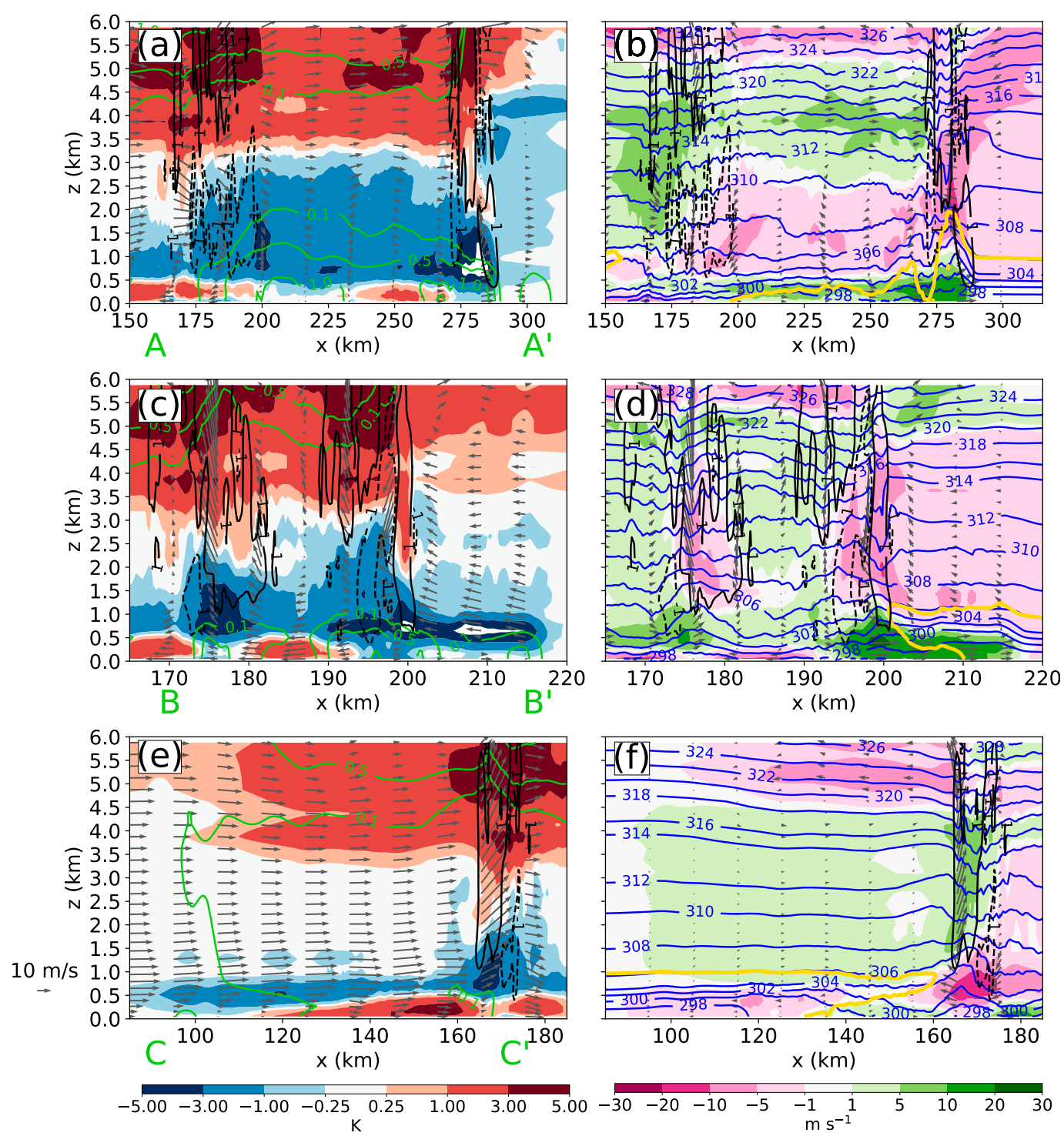

FIG. 5. Cross sections through (a),(b) A-A'; (c),(d) B-B'; (e),(f) C-C' after $4 \mathrm{~h}$ averaged over a width of $3 \mathrm{~km}$. (left) $\theta_{\rho}^{\prime}(\mathrm{K})$ in shaded contours, $w\left(\mathrm{~m} \mathrm{~s}^{-1}\right)$ in black contours, \pm 0.5 - and $1-\mathrm{Pa} P^{\prime}$ in green contours, and Earth-relative wind vectors. (right) Wind perturbations $\left(\mathrm{m} \mathrm{s}^{-1}\right)$ in shaded contours and vectors, $\theta(\mathrm{K})$ in blue contours, and $w$ $\left(\mathrm{m} \mathrm{s}^{-1}\right)$ in black contours. Gold contours represent the presence of $80 \%$ of passive tracer initialized in the lowest $1.5 \mathrm{~km}$. Magnitude of $w$ multiplied by 10 in plotted vectors for emphasis. Wind perturbations are vectors projected onto the plane of the cross section.

their level of free convection (LFC; Fig. 8). At the time shown in Fig. 8, it appears that the bore initially reduces the distance parcels in the 1-2-km layer need to travel to reach their LFCs (or $\Delta z_{\text {lfc }}$ ) to $<300 \mathrm{~m}$. This layer persists (with some oscillations in depth) through the passage of the bore, but disappears in the region where $800 \mathrm{~m}-2 \mathrm{~km}$ parcels experienced descent ahead of the updrafts $(x=$ $145-160 \mathrm{~km}$ ). The $\Delta z_{\text {lfc }}$ only appears to be reduced again in the few kilometers ahead of the ROD updraft in association with an increase in the height of the $\theta$ surfaces. In other words, the region of descent that follows the crest of the bore has a restabilizing effect before parcels reach ROD updrafts.

Updrafts are collocated with an upward perturbation in the isentropes between 1 and $2 \mathrm{~km}$ and a notable oscillation in wind and a pressure (Figs. 5e,f). Parcels above $\sim 800 \mathrm{~m}$ approaching from the southwest that encounter this elevated perturbation, are lifted sufficiently to reach their LFCs. So unlike Peters and Schumacher (2015a) and Blake et al. (2017), and the region of ROD shown in cross section B-B' (Fig. 5c) that remains tied to the leading line, in region of ROD2, 

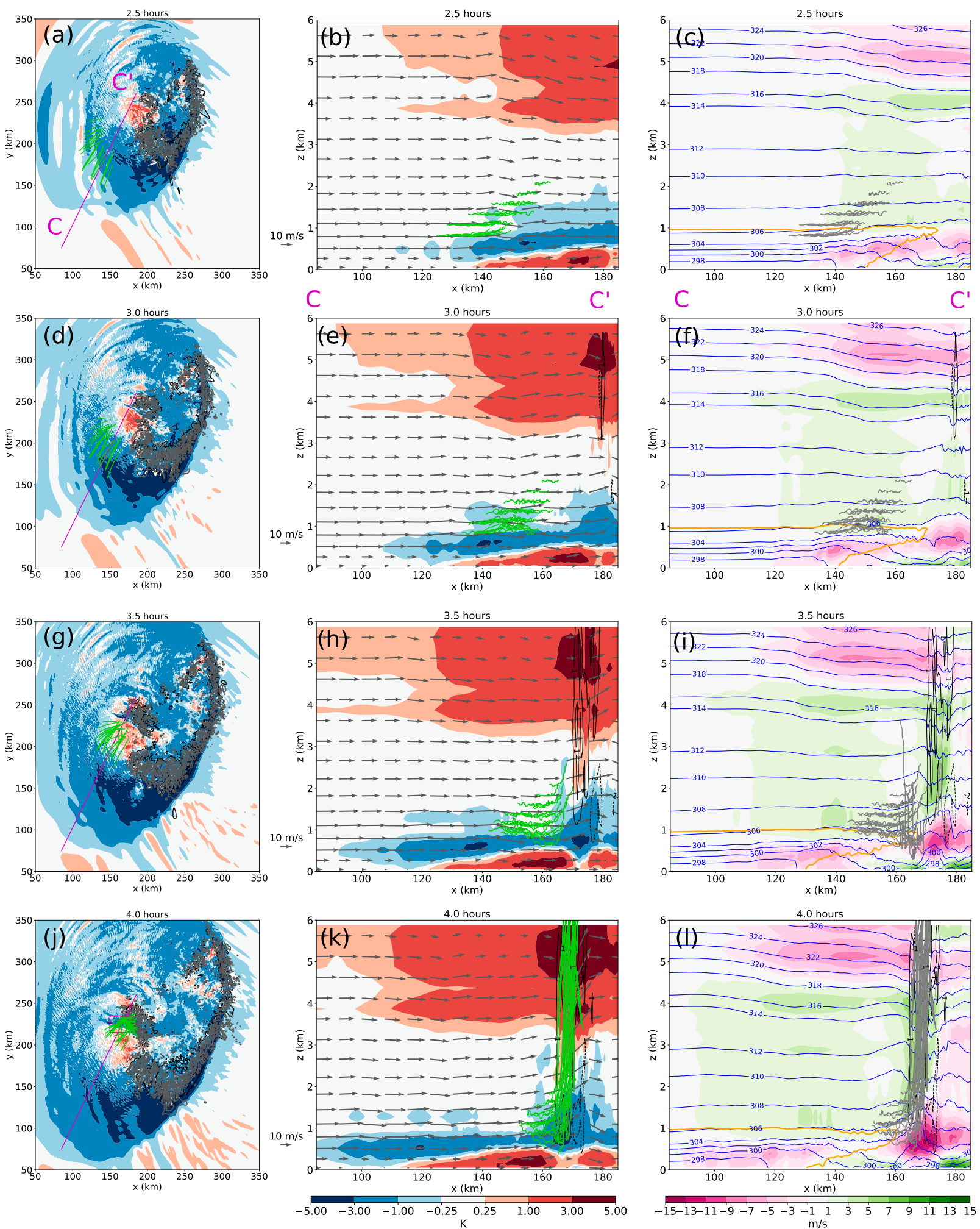

FIG. 6. (a),(d),(g),(j) $\theta_{\rho}^{\prime}$ (K; shaded) at $0.5 \mathrm{~km}$, and $40-\mathrm{dBZ}$ reflectivity (black contours). Green lines trace path of parcels that reach $5 \mathrm{~m} \mathrm{~s}^{-1}$ in a small region [indicated by magenta box in (j)] of ROD updrafts. (b),(e),(h),(k) Cross section through C-C $\mathrm{C}^{\prime}$ of $\theta_{\rho}^{\prime}(\mathrm{shaded}), w$ (black contours), and Earth-relative wind vectors. Green lines as in previous column. (c),(f),(i),(l) Cross section of wind perturbations (shaded), $\theta$ (blue contours), and $w$ (black contours). Gray lines now represent parcel paths. Cross sections are averaged over a width of $3 \mathrm{~km}$. 
parcels that encounter the initial boundary in the far southwest return nearly to their starting heights prior to being lifted into ROD updrafts. There is even evidence that parcels restabilize as they descend behind the bore (and ahead of the ROD updrafts). Instead, we propose that in this case, ROD parcels are lifted by a combination of the convective outflow in the form of an intrusion (discussed further below) and the gravity waves it generates, favorably amplified by the vertical wind shear profile over the same layer in an application of theories of Rotunno et al. (1988, hereafter RKW), Schmidt and Cotton (1990), and French and Parker (2008).

There are a number of unique, and intriguing behaviors in this simulation, and the explanations provided thus far leave a number of questions unanswered. Why is there warming at the surface and cooling in an elevated layer? Why do some regions of the elevated cooling appear to behave like a cold pool, and why are they deeper in some places than others? There must be downdrafts throughout the MCS, so what happens to the actual air associated with the convective downdrafts if surface cold pools are weak? What is an intrusion, and how might it explain some of these features? The behavior of convective downdraft air that reaches the boundary layer is complex, influenced by strong wind shear that changes direction with height and strong near-surface stability. In the following sections, we will build a conceptual model, using dry 2D simulations and simplified schematics to help answer these questions, and to more generally improve understanding of the interaction of convective outflow with a strong stable layer in sheared conditions.

\section{c. Building a conceptual model}

It is helpful to build a conceptual model of the ongoing processes in pieces, starting with what happens to downdrafts when they first interact with a stable layer, then adding one-dimensional wind shear with different configurations, and finally considering threedimensionality and convective feedbacks. It seems prudent to point out here that while we are building a conceptual model to help explain several features of this simulation, it is by no means an exhaustive model for capturing all processes observed. Similarly, while the 2D simulations may not produce exact replicas of every feature in the 3D simulations, they are still useful to visualize the fundamental response of this environment to the simplest kind of convection. The intention is to broaden the scope of the existing framework that we currently use to think about nocturnal MCSs, and highlight the critical importance of the three-dimensionality of the vertical wind shear profile. In the future, our hope is that this might be modified and improved upon to provide a more holistic understanding.

\section{1) 2D HEAT SINK EXPERIMENT SETUP}

Dry, 2D simulations were initialized by placing a $-0.03 \mathrm{~K} \mathrm{~s}^{-1}$ heat sink with a vertical radius of $1 \mathrm{~km}$, and a horizontal radius of $2 \mathrm{~km}, 2 \mathrm{~km}$ above the surface. Three different 2D simulations are shown here ${ }^{2}$ : one with no wind (2DU0), one with a wind profile consistent with cross section $\mathrm{A}-\mathrm{A}^{\prime}$ and approximately perpendicular to the leading line at that location in Fig. 4a (hereafter referred to as 2DT), and one with a wind profile consistent with cross section C-C' (Fig. 4a) and perpendicular to the ROD region (approximately parallel to the leading line; thus, hereafter referred to as 2Dll) of the wind profile used in the 3D simulations discussed previously. Both simulations had the same temperature profile, as well as vertical and horizontal grid spacing as the original simulation. The domain translation was set to 9 and $8 \mathrm{~m} \mathrm{~s}^{-1}$ for the 2DT and 2Dll simulations, respectively. In the dry heat sink simulations, it was possible to initialize passive tracer in the same location as the heat sink in order to track the mass of the hypothetical downdraft as it interacts with the boundary layer. In the original 3D simulations, it is significantly more difficult to trace downdraft air in this way. Instead, tracer was placed in the lowest $1 \mathrm{~km}$ under the preface that since a density current transports mass, it should also replace mass. In other words, removal of tracer may act as a proxy for identifying convective outflow that does not present in typical surface cold-pool fashion. This idea was tested in the 2D simulation by comparing the evolution of passive tracer initialized in the heat sink to the evolution of the passive tracer initialized in the lowest $1 \mathrm{~km}$. The region where $20 \%$ of the passive tracer was removed in the layer below $1 \mathrm{~km}$ (indicated by the downward perturbation of the $80 \%$ contour) was consistently nearly identical to the region where more than $25 \%$ of the passive tracer initialized in the heat sink was present through much of the simulation (not shown). Though there are more processes that may contribute to the removal of tracer in the 3D simulation, the removal of passive tracer may still be a valuable way to identify convective outflow in environments where it does not present as a cold pool. In the future, a series of experiments that explore these downdraft/stable layer/vertical

\footnotetext{
${ }^{2}$ Many more have been explored, including heat sinks of different strengths, sizes, and other methods of initialization. This method produces the most robust signal, but the general findings were consistent between methods.
} 

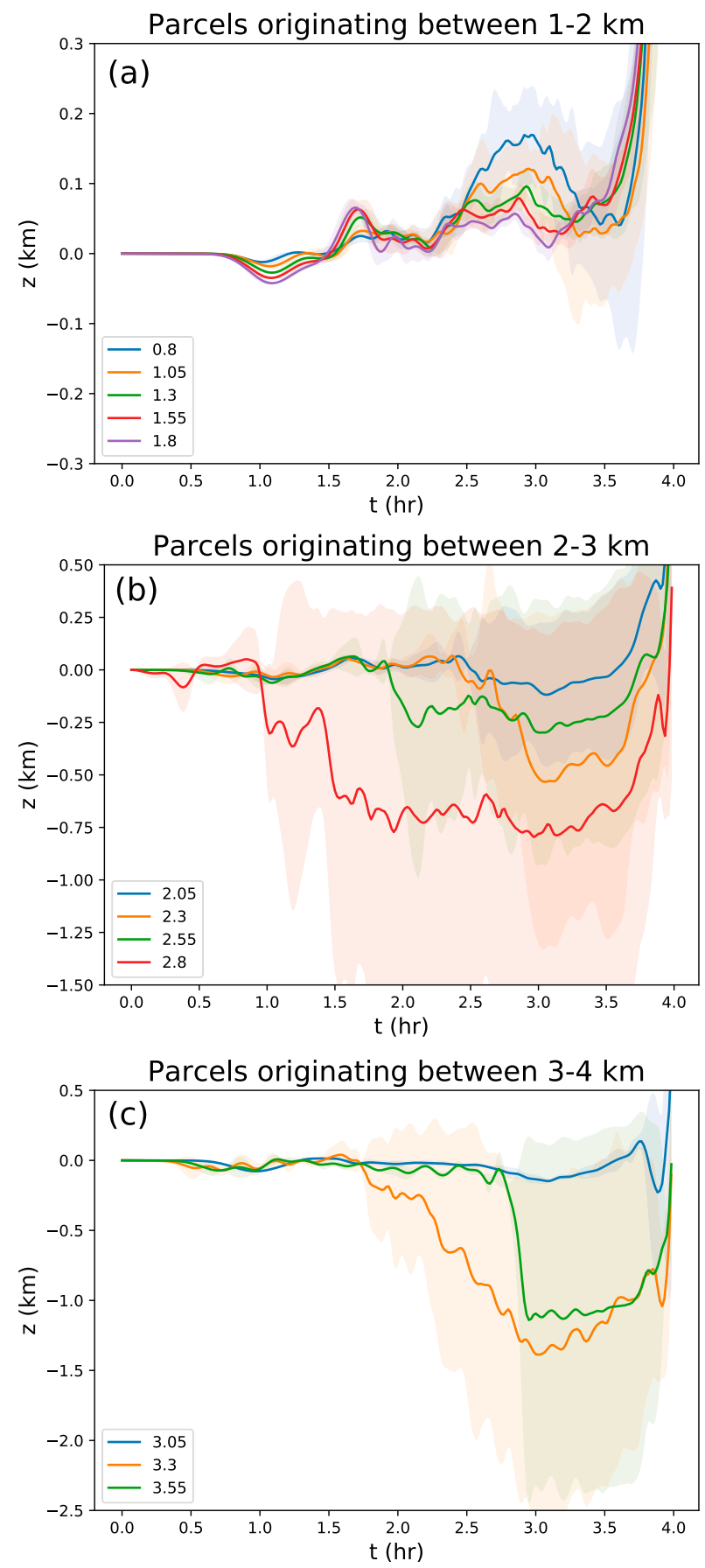

FIG. 7. Change in parcel height since time $t=0$ for parcels that reach $5 \mathrm{~m} \mathrm{~s}^{-1}$ in a region of ROD updrafts. Averages and standard deviations shown by initial parcel height for parcels originating (a) between $800 \mathrm{~m}$ and $2 \mathrm{~km}$, (b) between 2 and $3 \mathrm{~km}$, and (c) between 3 and $4 \mathrm{~km}$.

wind shear interactions with simplified stable layers and vertical wind shear profiles and with cooling of different strengths and widths could be valuable, but are beyond the scope of this current work.

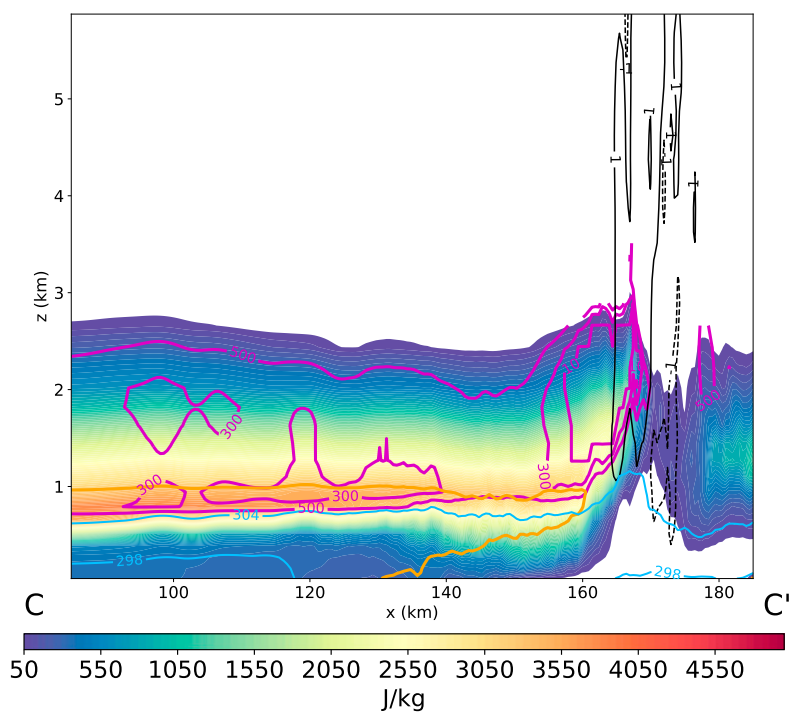

FIG. 8. Cross section through C-C' (Fig. 4a) of CAPE ( $\mathrm{J} \mathrm{kg}^{-1}$; shaded) and $\Delta z_{\text {lfc }}(\mathrm{m}$; magenta contours) for parcels lifted from each level after $4 \mathrm{~h}$. Vertical velocity of $\pm 1 \mathrm{~m} \mathrm{~s}^{-1}$ (black contours), $\theta_{\rho}=298,304 \mathrm{~K}$ (blue contours), and passive tracer initialized below $1.5 \mathrm{~km}=80 \%$ plotted for reference (orange contour). Cross section is averaged over a width of $3 \mathrm{~km}$.

\section{2) INTRUSIONS}

Consider the first updrafts: some perturbation pushes elevated parcels to their LFCs, where they rise on their own, and eventually form large enough droplets that they begin to rain. With evaporation and melting, the first downdrafts form. But what actually happens when those downdrafts first reach the strong stable layer near the surface? In an environment absent of vertical wind shear, the downdrafts impinge on the stable layer, generating a warm perturbation at the surface and a cool perturbation aloft (Fig. 9a). The passive tracer descends with the downdraft, reaches the surface below the point of impingement but primarily spreads out in an elevated layer. Regions of cooling over warming are evidence of an increase in distance between isentropes in an elevated layer (examine the distance between the 302- and 306-K isentropes in Fig. 9b). This collocated with passive tracer bears resemblance to a feature called an intrusion.

In an instance with two fluid layers, an intrusion occurs when a third fluid is introduced that has a density less than that of the bottom layer, but greater than that of the top layer. In this scenario, an intrusion then travels along the interface, with a density between the densities of the layers (Rottman and Simpson 1989). In the present simulation, the fluid is stratified, but given the strong low-level stability, it is reasonable to expect that downdrafts (especially early in the simulation) may actually be less dense than a layer near the surface, and 

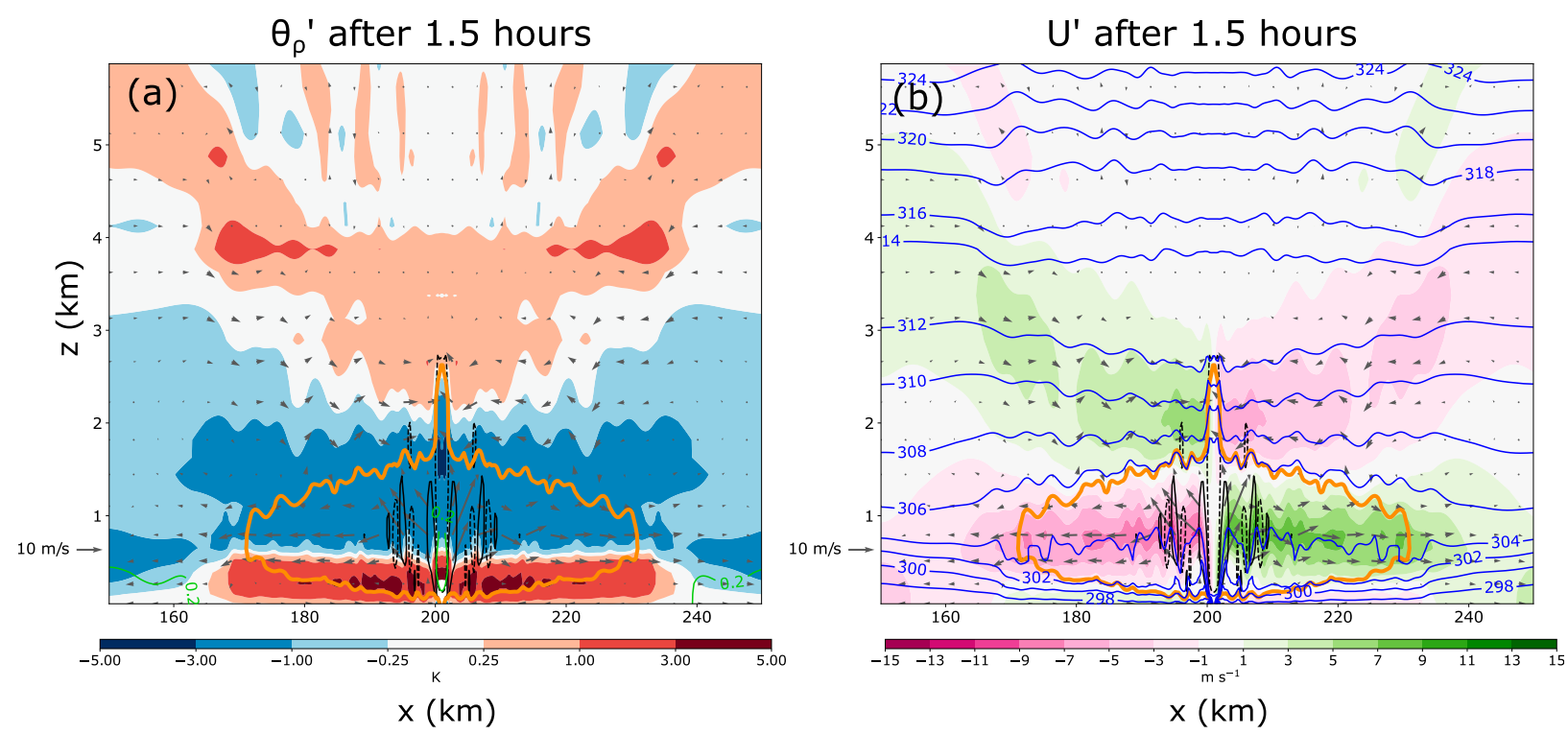

FIG. 9. Results of a dry, 2D heat sink initialized in a quiescent environment after $1.5 \mathrm{~h}$ (2DU0 experiment). The orange line is the $25 \%$ contour of the amount of passive tracer that has been added to the simulation at a source point by this time. (a) $\theta_{\rho}^{\prime}\left(\right.$ shaded), $w= \pm 1 \mathrm{~m} \mathrm{~s}{ }^{-1}$ (open black contours), $P^{\prime}$ (hPa; open green contours), and wind perturbation vectors. (b)Wind perturbations from $t=0$ (shaded regions and vectors) and $\theta$ (blue contours).

so when they encounter that layer, they begin to spread out on top of it, generating waves (e.g., cool perturbations at $x=160,240$ in Fig. 9) ahead of, above and below it-like an elevated cold pool. In fact, an intrusion can be thought of like two density currents, one "right side up" and one "upside down"-both still driven by density gradients (e.g., Ungarish 2005, 2009; Fig. 10 provides examples from Ungarish 2009; Sutherland and Munroe 2014). In this environment, the stratification below the intrusion is greater than above it, and it is likely that the "right side up" current dominates, giving the appearance of an elevated cold pool (Fig. 9).

Another way to think about this is like an upside down overshooting top, in other words, an overshooting downdraft. A downdraft penetrates the stable layer, overshoots its equilibum level (the level with equivalent density), and moves through a layer near its equilibrium level like an anvil (here, the intrusion). As it moves, it increases the distance between the surrounding isentropes, which leads to the cooling over warming structure observed. Similar to cold pools that reach the surface, intrusions can generate gravity waves and bores.

An important difference between the intrusion described here and most existing studies of intrusions, is that existing studies are done in stagnant flow (i.e., no wind shear) (e.g., Sutherland et al. 2004; Flynn and Sutherland 2004; Ungarish 2005, 2009; Flynn and Linden 2006; Sutherland and Munroe 2014). Bluestein et al. (2017) presents analysis that compares structures observed associated with a prefrontal wind shift to that of an intrusion, while Physick et al. (1985) describes observations that suggest that convective outflow associated with an Australian squall line leads to a reduction of the height of a strong nocturnal inversion. They essentially describe an intrusion, noting that outflow was potentially cooler than the undisturbed air above, but warmer than the air below, similar to vertical profiles through the region of warming in this simulation (discussed in more detail in section $3 a$ ) and observations collected during PECAN. The term elevated cold pool (as mentioned previously to describe the intrusion) may perhaps be a more intuitive description, but the actual processes are more complex. Both "right side up" and "upside down" currents must be considered.

\section{3) INTRUSIONS AND VERTICAL WIND SHEAR}

What happens now, if the first downdrafts encounter strong vertical wind shear as they penetrate the stable layer? It is useful to think about this from the perspective of cross section $\mathrm{A}-\mathrm{A}^{\prime}$ (and 2DT) first, which has nearly unidirectional vertical wind shear. The evolution of thermodynamic and wind fields in the 2DT simulation after $45 \mathrm{~min}$ resemble those observed in the cross section through $\mathrm{A}-\mathrm{A}^{\prime}$ after $1.5 \mathrm{~h}$ (Fig. 11). As in the 2DU0 run, there is a large warm perturbation below a cool perturbation aloft. The passive tracer remains more elevated, but the warm perturbation at the surface is still a direct result of the intrusion. In the 3D simulation, the removal of the passive tracer collocated with the warm perturbation suggests that a nonnegligible portion 
(a)

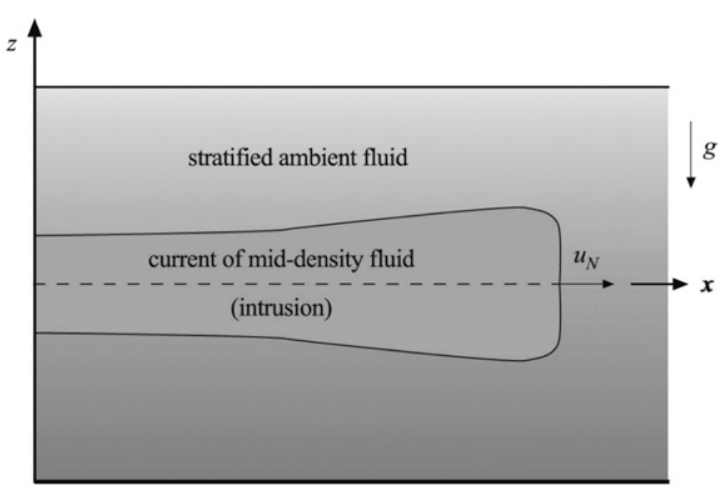

(b)

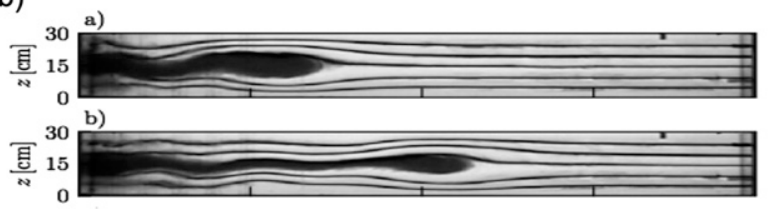

FIG. 10. (top) Simple conceptual model of an intrusion of a "mixed" fluid into a stratified ambient fluid from Ungarish (2009, their Fig. 1.1d). (bottom) Two snapshots of a laboratory generated intrusion in a uniformly stratified fluid (Sutherland and Munroe 2014).

of the convective downdraft reaches the surface (Fig. 11a). Over time, the intrusion moves west in the upshear direction, which is predominately downwind. ${ }^{3}$ It remains nearer to the surface than in 2DU0, and cool perturbations associated with the top half of the intrusion decrease as it moves away from its source. In contrast, the intrusion is apparently unable to propagate in the downshear/upwind direction, at least through density current processes. To do this, the density gradient between the top half of the intrusion and its surroundings would need to be large enough for the density current speed to be greater than that of the wind speed, yet the density of the intrusion air would still need remain less than the air below. This may be feasible in a scenario where the stability decreases even more rapidly with height, but is not the case here. While it becomes difficult to distinguish the intrusion from its source, large upward perturbations on the downshear side of the intrusion/heat sink are amplified between 1 and $2 \mathrm{~km}$ (Figs. 11c,d compare with Fig. 9). They appear to break, and lead to relatively large wavelike perturbations in $\theta$ and wind in the stable layer. These move downshear ahead of the downdraft/intrusion, maintain their amplitude, and are indicative of a bore (Fig. 11). This bore can also be seen in the 3D simulation (Figs. 11a,b). While multiple updrafts and downdrafts accompany the bore in the 2D simulation, it is notable

\footnotetext{
${ }^{3}$ In a storm relative sense.
}

that a relatively consistent updraft persists between 1 and $2.5 \mathrm{~km}$ on the downshear/upwind side of the amplified upward perturbations. In the warm bubble simulation, some of the cooling above $1 \mathrm{~km}$ is an adiabatic response to lifting beneath the updraft, similar to the processes described in Schmidt and Cotton (1990) and Schumacher (2009) (Fig. 11a), but similar cooling exists in an elevated layer in the $2 \mathrm{D}$ simulation in the absence of strong, sustained updrafts (no moisture; Fig. 11c).

Several studies have described the impact of the vertical wind profile on density current and wave structures and the resulting vertical motion (e.g., Rotunno et al. 1988; Schmidt and Cotton 1990; Xu 1992; Klemp et al. 1994; Liu and Moncrieff 1996; Xue et al. 1997; Weisman and Rotunno 2004). Liu and Moncrieff (1996) found the height of the density current head was dependent on its propagation relative to the mean flow in an unsheared environment (deeper when propagating upstream and shallower propagating downstream). RKW noted that cold pools produce deeper lifting on the downshear side of the cold pool. They describe an optimal state in which the horizontal vorticity generated by the buoyancy gradient at the edge of the density current is balanced by the horizontal vorticity associated with the vertical wind shear. In a "revisit" of this, Weisman and Rotunno (2004) also found that cold pool depth (and strength) increased with increasing shear, up to an optimal state (cold pool speed $c \approx$ bulk wind difference over the layer $\Delta U$ ), but then decreased again if shear was further increased. Similarly, Schmidt and Cotton (1990) demonstrate that vertical wind shear acts to modulate the amplitude of low-level gravity waves. Critically, they show that stronger shear results in a higher amplitude wave on the downshear side. In their $2 \mathrm{D}$ simulations with a stable boundary layer, this wave amplification was instrumental to lifting parcels to their LFCs. Since then, many others have applied these concepts in different scenarios to better understand the interactions of convective outflow and different configurations of vertical wind shear.

Taken together, the above studies suggest that up to some shear threshold, we can expect enhancement of upward isentrope perturbations (wave or density current), and acceleration of positive vertical motion in the downshear direction. The relative direction of the vertical wind shear vector and mean flow can either act to enhance, or diminish this effect. Very strong shear can lead to wave breaking, and in the case of a surface density current, a reduction in its height.

The intrusion's behavior is dependent on any number of factors: magnitude, width, and depth of the initial perturbation, the motion of the downdraft relative to the 

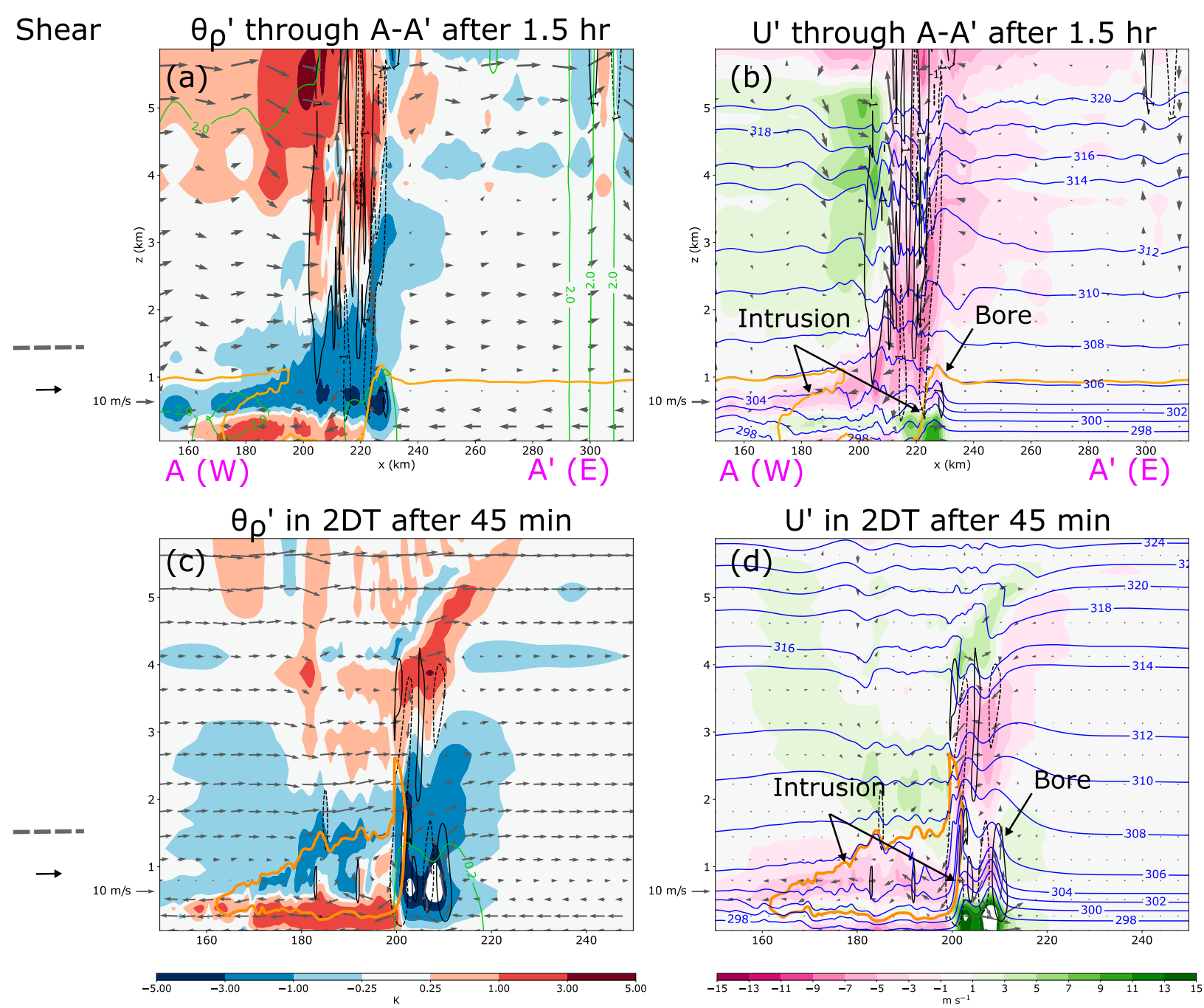

FIG. 11. (top) Cross section (averaged over a width of $3 \mathrm{~km}$ ) through $\mathrm{A}-\mathrm{A}^{\prime}$ (Fig. 4a) but after $1.5 \mathrm{~h}$. The orange line is the contour of $80 \%$ (think of the decrease below $1 \mathrm{~km}$ as $20 \%$ removal) of the passive tracer initialized below $1 \mathrm{~km}$. (bottom) Results of a dry, 2D heat sink initialized with the same wind profile as cross section A-A' (approximately perpendicular to the leading line) after 45 min (2DT experiment). The orange line represents passive tracer as in Fig. 9. (a),(c) $\theta_{\rho}^{\prime}$ (shaded), $w= \pm 1 \mathrm{~m} \mathrm{~s}^{-1}$ (open black contours), and Earthrelative wind vectors; and (b),(d) wind perturbations from $t=0$ (shaded regions and vectors) and $\theta$ (blue contours).

mean flow, the strength and orientation of vertical wind shear and relevant shear layers, the relationship between the height of shear reversal (in a LLJ) and the equilibrium level, and more. We could not possibly hope to detail the effects each of these have in this one analysis. Instead, we present an idealized version of the 2DT experiment, with low-level unidirectional westerly vertical wind shear is presented in Fig. 12; the vorticity associated with the shear is positive everywhere. On the downshear side of the intrusion (right), negative vorticity is generated by the buoyancy gradient above the equilibrium layer, while positive vorticity is generated below. This results in favorable kinematic lifting above the equilibrium layer on the downshear side. The intrusion below the equilibrium layer is also less dense than its surroundings, leading to upward buoyant forces. Below the equilibrium layer, the vorticity pairing is unfavorable for vertical motion, but generates an acceleration vector that points to the right around the equilibrium level. In the case where mean storm-relative wind in the layer of the intrusion is in the same direction (or zero), the right side of the intrusion propagates toward the right. In our example, the domain translation effectively subtracts $9 \mathrm{~m} \mathrm{~s}^{-1}$ everywhere in the vertical wind profile, as if the heat sink was moving at that speed toward the east. This is apparently faster than the intrusion speed, but the result is still an amplification of upward isentrope perturbations, implied increased 


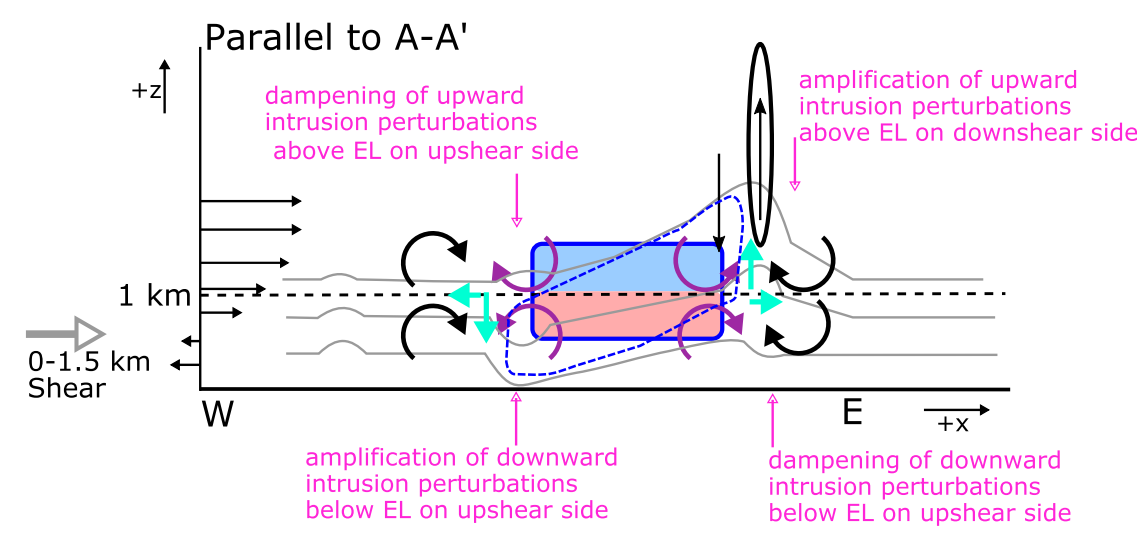

FIG. 12. (a) Schematic diagram showing the idealized behavior of an intrusion in unidirectional vertical wind shear. The equilibrium level is given by the dashed black line. A simplistic idealized intrusion before the effects of vertical wind shear are considered is shown by solid royal blue lines. The light blue color shading indicates the relative negative buoyancy of the intrusion prior to modification by vertical wind shear. The pink color shading indicates the relative positive buoyancy of the intrusion prior to modification by vertical wind shear. The idealized intrusion after consideration of the effects of vertical wind shear is shown by the dashed royal blue line. The purple arrows indicate vorticity tendency generated by the buoyancy gradient, while the black arrows represent the vorticity tendency associated with the vertical wind shear. The resulting acceleration vectors due to the interaction of baroclinicly generated and shear-associated vorticity are shown by the teal arrows. Isentropes approximated by the shear-modified intrusion are shown in gray.

convergence, and consequently enhanced vertical motion on the downshear/upwind side between 1 and $2 \mathrm{~km}^{4}$ In the 3D simulation, the speed of the propagation of the leading line in some places (like $\mathrm{A}-\mathrm{A}^{\prime}$ ) suggests that the initial lift may be driven by the bore in those locations (seen ahead of the intrusion in Figs. 5a, 5b, and 11). However, the bore is continually reinforced by new downdrafts and subsequent intrusion, as suggested by the $2 \mathrm{D}$ simulations, and we can also expect enhanced vertical motion on the downshear/upwind side of the downdrafts/intrusion, as shown in the above analysis. The combination of the effects from the bore, intrusion, and adiabatic response to lifting lead to an elevated structure that resembles an elevated cold pool, but is indeed more complex (Figs. 5a,b).

On the upshear/downwind side of the intrusion (left), similar logic leads to dampening of the upward perturbations above the equilibrium layer, and amplification of downward perturbations much like seen in Figs. 11a and $11 \mathrm{c}$ (though the motion generated by the vorticity pairing opposes buoyancy forcing below the equilibrium layer in this case). In this direction, the intrusion propagates with the storm relative wind, and remains nearer to the surface despite the opposing upward buoyant force (Fig. 12). This leads to persistent warm perturbations

\footnotetext{
${ }^{4}$ There are also waves and associated perturbations between 2 and $3 \mathrm{~km}$, but these may be an artifact of the heat sink.
}

near the surface like those seen in both $2 \mathrm{D}$ and $3 \mathrm{D}$ simulations.

In other words, on the downshear/upwind side (right), upward perturbations associated with both the intrusion and bore are amplified, leading to upward acceleration and positive vertical motion. On the upshear/downwind (left) side, the intrusion spreads west, is dampened, but remains near the surface. This helps to explain the broad warming at the surface, cooling aloft, and largest $\theta_{\rho}$ perturbations at the leading edge of the MCS. However, this does not yet explain the ROD. For this, we need to consider another dimension.

It is more difficult to make a direct comparison of the 2Dll experiments to the 3D simulation, since there were four bubbles used in the 3D experiments, and any northsouth cross section will contain elements of the interaction between these bubbles not considered here. However, for the sake of the interaction of the LLJ dominated component of the vertical wind shear and the intrusion, the heat sink still provides a useful illustration. As in the previous two $2 \mathrm{D}$ experiments, there are $\theta_{\rho}$ increases near the surface and $\theta_{\rho}$ decreases aloft coincident with passive tracer. Upward perturbations coincident with the heat sink are amplified, and a persistent updraft forms to the south in the 12-km layer. Gravity waves are generated in different layers in either direction (Fig. 13). Interestingly, there is also a large positive perturbation in $\theta_{\rho}$ not coincident with passive tracer, but rather just below the heat sink 

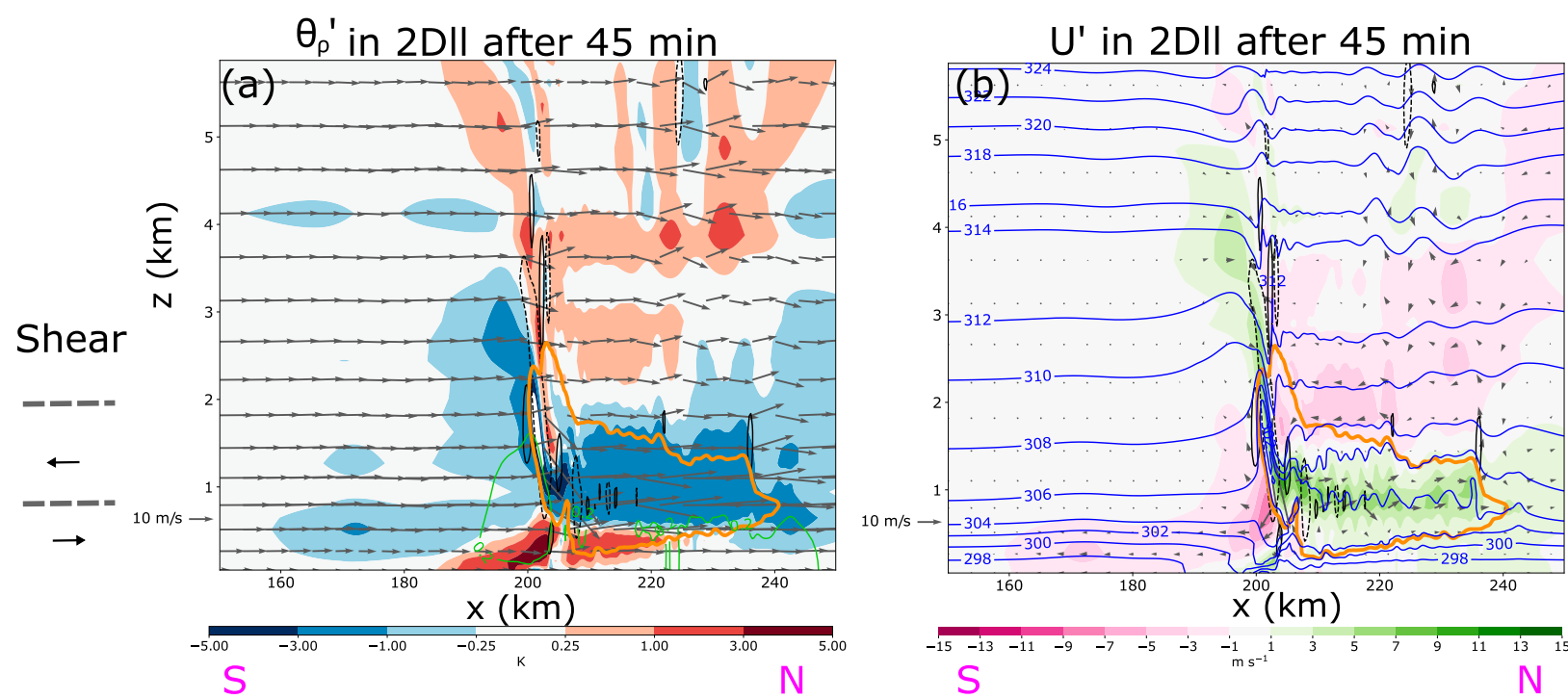

FIG. 13. Results of a dry, 2D heat sink initialized with the same wind profile as cross section C-C' (approximately perpendicular to the ROD region, and parallel to the leading line) after $45 \mathrm{~min}$ (2Dll experiment). The orange line represents passive tracer as in Fig. 9. Panel contours and vectors are identical to Figs. $11 \mathrm{c}$ and $11 \mathrm{~d}$.

that likely results as an adiabatic response to the heat sink. Additional discussion of warm perturbations will be provided in section $4 \mathrm{a}$.

The wind profile in this direction is dominated by a strong LLJ. Given the relatively strong southerly flow through the depth of the intrusion, it propagates toward the north. However, associated isentrope perturbations and resulting vertical motion is also impacted by the vorticity in the relevant layers. At the LLJ maximum, the sign of the vertical wind shear (and associated vorticity) will change. If shear is considered in a layered sense, like in French and Parker (2010) and Peters and Schumacher (2015b), but where the layers are determined by their relation to the LLJ maximum, we can construct a model of how it might interact with the intrusion (Fig. 14). For simplicity, we are assuming that the LLJ maximum is at approximately the same height as the equilibrium layer.

To the south above the equilibrium layer, the negative shear-associated vorticity and positive buoyancy-generated vorticity lead to an upward acceleration vector, while below the equilibrium layer, the opposite processes leads to a downward acceleration vector (Fig. 14). To the north, the vorticity pairing is not conducive to vertical motion, but rather favors propagation to the north. The effect of this, is a widening of the intrusion to the south and a narrowing to the north as the leading edge of the intrusion propagates rapidly away from its source. In this simulation, the widest part of the intrusion is actually slightly north of the downdraft (between $x=200$ and 210), likely a result of the strong southerly flow.
In tests with stronger or wider heat sinks, the southern edge of the intrusion becomes effectively stationary (not shown). The northern edge of the intrusion in Fig. 13 is narrower, and dominated by elevated cool perturbations. ${ }^{5}$ The slight differences between northern portion of the schematic and the 2Dll experiments can be explained by a few things, but most notably, the simplified schematic does not account for the stronger stratification below the top of the stable layer. In the absence of kinematic forcing in the vertical, the "right side up" current would dominate.

What this means, is that parcels approaching the intrusion from the south in a layer above the equilibrium layer, like the ROD parcels described in section $3 b$, would encounter isentropes perturbed upward and kinematic lifting at the edge of the intrusion.

\section{4) SUMMARY OF PROCESSES}

In an environment with a strong low-level stable layer, downdrafts that are potentially warmer than the surface may overshoot their equilibrium layer, and warm the surface upon reaching it. The downdraft air may then spread out in a layer of approximately equivalent density, effectively spreading isentropes around it. In an environment with vertical wind shear, the shear profile modifies the structure of this intrusion, and the relative flow at its edges. An application of RKW theory to the

\footnotetext{
${ }^{5}$ Note that the narrowing will also be a function of the distance of the intrusion head from the source (Fig. 9).
} 


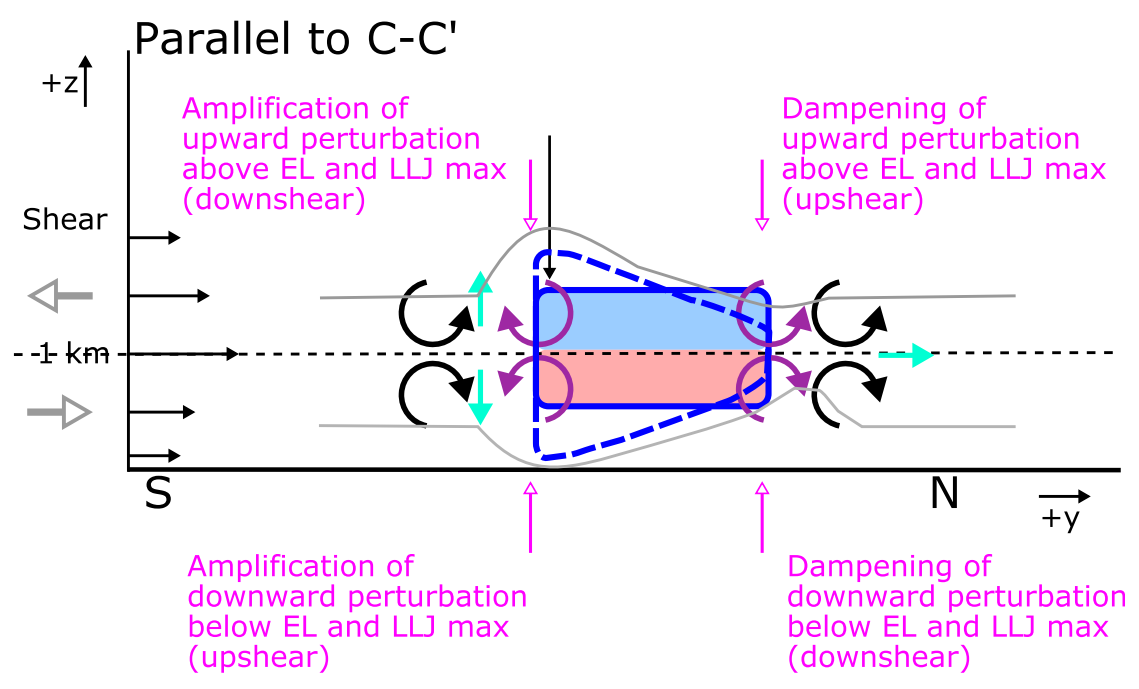

FIG. 14. Schematic diagram showing the idealized behavior of an intrusion in an environment with an LLJ vertical wind shear profile. Notation is as in Fig. 12.

intrusion that takes into account the three-dimensionality of the wind profile and the LLJ shear reversal can help to explain the structures observed but cannot explain everything. Waves (and a bore) are generated by the intrusion are amplified (dampened) in the downshear (upshear) direction by layer-relevant vertical wind shear (via Schmidt and Cotton 1990; French and Parker 2010). These wavelike features are most likely responsible for propagation along parts of the leading line but play only modest roles elsewhere.

ROD parcels that encounter the leading gust front boundary from the southwest interact with the boundary but are not sufficiently lifted, and nearly return to their starting height prior to being lifted by the intrusion above the equilibrium layer. If the processes that support ROD convection can be considered similar to those modeled by the $2 \mathrm{D}$ simulations, then it is possible to apply the simplified schematics to help explain the support of ROD.

Figure 15 provides a 3D schematic of several of the basic processes described so far. The potentially warmer intrusion air near the surface from the earliest downdrafts spreads out along the surface toward the west, while the potentially cooler intrusion air in a more elevated layer spreads toward the northwest, giving this intrusion a complex three-dimensional structure (shown by shades of blue/pink) driven by a combination of gradients in potential temperature and the changing winds with height. Intrusions lead to a spreading of isentropes, perturbing isentropes below them downward (warm perturbations) and perturbing the isentropes above them upward (cool perturbations) like a surface-based cold pool. The intrusion generates wavelike features that propagate in all directions, that are modified by the vertical wind shear.

To understand the lifting that supports ROD convection, we have to consider the three-dimensionality of the environment. As the initial intrusion spreads to the west and northwest, it is also amplified along its southern edge to varying degrees. Above the equilibrium layer, this may once again lead to an upward perturbation of isentropes, but now offset some distance behind the leading line.

In the instance of the ROD that remains close to the leading line (ROD1), the bore generated at the leading edge is not sufficient to lift parcels with a more southerly trajectory to their LFCs, but they remain elevated or continue to rise until they encounter the density current some distance behind, where they are lifted into updrafts, much like in Blake et al. (2017). Here, we use the more general term density current, rather than trying to distinguish between a cold pool and an intrusion, as Figs. $5 \mathrm{c}$ and $5 \mathrm{~d}$ indicates that the density current has some properties of both; there are cool perturbations at the surface directly under the strongest updrafts, but warm perturbations elsewhere, and evidence that downdraft air reaches the surface (passive tracer removed indicated by gold line). What is key though, is that either one could give parcels the extra boost needed to reach their LFCs.

In the instance of the ROD2, it turns out that the story is similar. Parcels approach from the southwest but are insufficiently lifted by the bore. Over their longer trajectory, parcels have time to descend behind the bore, before finally being lifted by the intrusion air located 


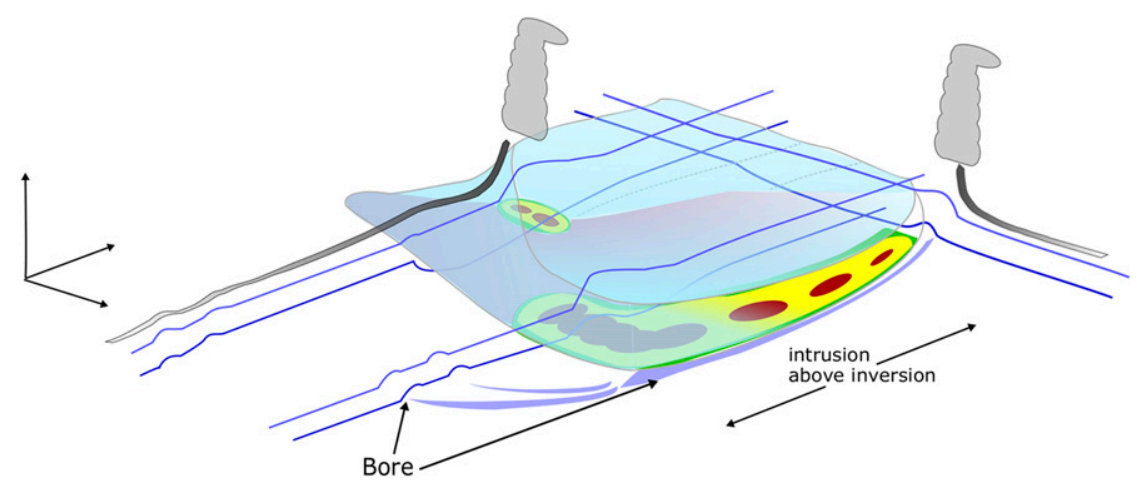

FIG. 15. Conceptual schematic of leading line and ROD support mechanisms. Our interpretation of the three-dimensional convective outflow is represented by the shaded light blue/pink structures. The pink hue represents the bottom portion of the intrusion below the equilibrium level, and the light blue represents the intrusion above equilibrium level. Example isentropes (blue lines) highlight the leading bore and the spreading of the isentropes by the convective outflow at different locations. Parcel paths (thick gray gradient lines) are shown for low-level parcels approaching from the east (as in Fig. 5a for $\mathrm{A}-\mathrm{A}^{\prime}$ ), and for parcels from above $1 \mathrm{~km}$ to the southwest (as in Fig. $5 \mathrm{c}$ for $\mathrm{C}-\mathrm{C}^{\prime}$ ). Solid/dashed gray lines help to give structure to the intrusion top/bottom.

above the equilibrium layer that is deepened by favorable vertical wind shear in the same layer.

\section{Discussion}

It is difficult to say whether the intrusion is what initiates the ROD, but our analysis suggests that the intrusion produced by the leading line plays a role. A number of other factors not explored here including wake region convergence, elevated shear parallel gravity waves (e.g., Liu and Moncrieff 2017), and bore lifting early in the MCS, may also contribute to initiation. Once initiated, the ROD convection will also produce its own downdraft, intrusions, waves, etc. and may be capable of supporting itself through the processes described above. In other words, even if downdrafts do not lead to cold pools, their resulting elevated outflow may be capable of supporting convection. So in cases with strong stability and weak (or nonexistent) surface cold pools that generate more often discussed waves and bores, we may not want to discount what happens to the actual convective downdraft air once it reaches the stable layer.

While convective cells everywhere throughout the MCS produce downdrafts, they are only potentially cooler than the surface in the region of heaviest precipitation at the southern edge of the leading line. It is not exactly clear what leads to the cooling at the surface in these locations. It is possible that the vertical wind shear profile-intrusion interaction is optimal in this location, generating stronger updrafts capable of drawing air from a deeper layer (tapping into CAPE in stable layer parcels) and ultimately producing heavier precipitation and stronger cooling. It may also be possible, that if a significant proportion of the stable air is lifted into the updrafts, the downdrafts do not actually have to penetrate a stable layer that is as strong as the preconvective environment (in short, perhaps strong updrafts further modify the environment in a favorable manner for cold pool development before the impact of downdrafts).

\section{a. A comment on the surface warming}

There are several possible reasons for the observed surface warming in the 3D simulation, any of which may occur at different times in different regions relative to the convection. In all three 2D simulations, near-surface passive tracer suggests that a nonnegligible portion of the convective downdraft reaches the surface, despite the strong stable layer. As has been discussed at length above, where the downdraft air is potentially warmer than the air near the surface, when it descends to the surface as an overshooting downdraft (and later, intrusion) the surface is warmed. It may also be that air near the top of the inversion is potentially warmer than the air at the surface, so when a downdraft penetrates that layer, it brings some of that inversion layer air down to the surface. Finally, as mentioned in the discussion of the 2Dll simulation, warming may also occur as an adiabatic response to the presence of the downdraft (similar to the waves generated in response to an updraft). Another mechanism that occurs more often in the wake region of an MCS is the descent of air in unsaturated downdrafts that warms adiabatically as it descends. This is more commonly understood as the mechanism that leads a wake low through an associated hydrostatic 

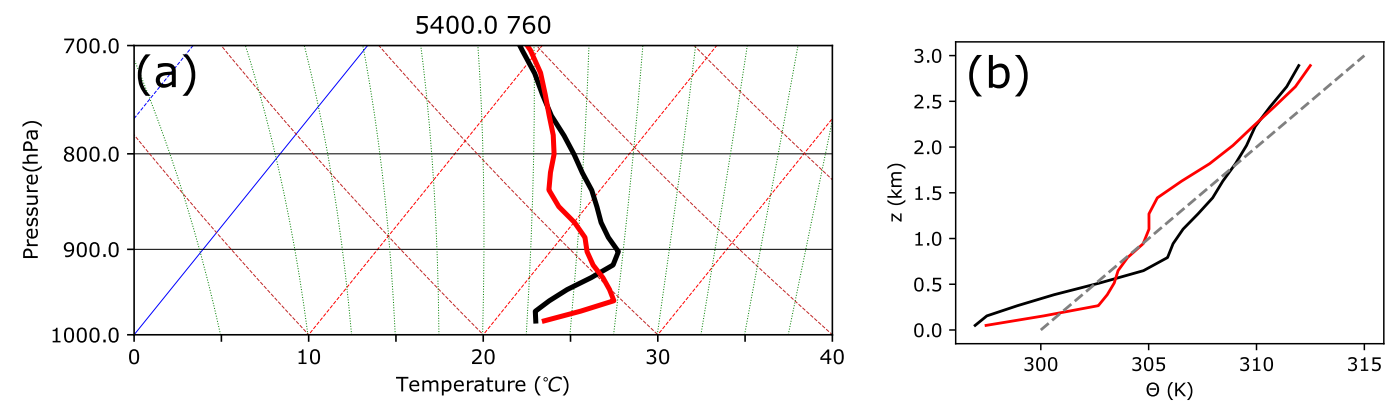

FIG. 16. Profiles through $x=190 \mathrm{~km}$ in Figs. 9c and 9d after $45 \mathrm{~min}$ (red) and the original temperature profile (black). (a)Temperature profiles on a skew $T-\log p$ diagram and (b) $\theta$ as a function of height. The gray dashed line is $5 \mathrm{~K} \mathrm{~km}^{-1}$.

reduction of surface pressure (like that of Fig. 4c; e.g., Johnson and Hamilton 1988). However, an unsaturated downdraft would still encounter the low-level stable layer, so multiple mechanisms may be at play.

At the location of the greatest observed $+\theta^{\prime}$ in the simple 2D experiment with no shear (2DU0), the surface warms but the greatest observed warming is in a layer above the surface (red line in Fig. 16). This effectively lowers the layer of conditional instability and the depth of the inversion. Cooling at near the top of the initial stable layer actually leads to some stabilization between 1 and $2 \mathrm{~km}$ (Fig. 16).

In the real atmosphere, and simulations with heterogeneous initial conditions, this sort of MCS often develops in an environment with a synoptic-scale northsouth temperature gradient that typically progresses with time and has a cooling effect in this same region. Nocturnal environments also tend to cool with time, and though the amount of cooling depends on a number of variables, this would also likely act to cool the region at the same time. Thus, this warming described above and observed in homogeneous simulations may not be as strong or as obvious in a more realistic environment.

\section{b. Elevated?}

Several studies, notably Parker (2008), French and Parker (2008), and Billings and Parker (2012), have begun a discussion of whether nocturnal convection is truly elevated-decoupled from the stable layer-or not. Even more recently, Parker et al. (2020) states that severe nocturnal MCSs often resemble their daytime surface-based counter parts. To examine this in a new way, Fig. 17 was constructed to address the question of what vertical level(s) the updrafts originate in the present simulation. Throughout the duration of the MCS, ascent rates below $1 \mathrm{~km}$ are greater than $2 \mathrm{~m} \mathrm{~s}^{-1}$ at some point in the $x$ direction in the $35-\mathrm{km}$ bounded portion, over nearly the entire near-storm region (Fig. 17c). After $1.65 \mathrm{~h}$ (marked by the first dashed line in Figs. 17c and 17d), the leading line moves out of the bounding box (Fig. 17a), and the gap between the two regions of ROD convection becomes visible. Between 1.5 and $2 \mathrm{~h}$, the MCS develops a stronger southerly component of motion (Figs. 17c,d). This southward progression is accompanied by near-surface ascent rates of $5 \mathrm{~m} \mathrm{~s}^{-1}$ in this region, even below $500 \mathrm{~m}$ in some places (Fig. 17d). In the mature MCS $4 \mathrm{~h}$ into the simulation, $5 \mathrm{~m} \mathrm{~s}^{-1}$ ascent rates were observed below $1 \mathrm{~km}$ in several locations along the leading line, and between 1.5 and $4 \mathrm{~km}$ in the region of ROD (Fig. 17b). The largest region of $5 \mathrm{~m} \mathrm{~s}^{-1}$ associated with the gust front boundary at the leading edge of the MCS is observed on southernmost edge of the MCS. Tests of other thresholds indicates that $2 \mathrm{~m} \mathrm{~s}^{-1}$ updrafts below $500 \mathrm{~m}$ are relatively continuous along the leading line. In Fig. 17b the first (from the ground up) instance of $5 \mathrm{~m} \mathrm{~s}^{-1}$ vertical velocities are observed closer to the surface along southern and eastern portions of the leading line than along the northern portion of the leading line.

As in Parker (2008), French and Parker (2010), and Billings and Parker (2012), passive tracer was placed in the lowest $500 \mathrm{~m}$. Since the stable layer in the input sounding was over $700 \mathrm{~m}$ deep, tracer lofted from below $500 \mathrm{~m}$ should be associated with stable air. One hour after initiation, less than $5 \%$ of the passive tracer has been lifted to $5 \mathrm{~km}$ (Fig. 18a). This corresponds to primarily elevated inflow after the initial warm bubble release. At $2 \mathrm{~h}$ into the simulation, updrafts appear to be making some transition from the west of the downdrafts to the east of the downdrafts (Fig. 18e). At this point, downdrafts have reached the stable layer. In fact, the shape of the tracer removed resembles the hypothesized shape of the intrusion (Fig. 12). After $4 \mathrm{~h}$, the MCS has matured substantially, and $10 \%-25 \%$ of tracer parcels placed in the lowest $500 \mathrm{~m}$ have been lofted to $5 \mathrm{~km}$ over a relatively large region in the southern half of the leading line (Fig. 18b). In some places, percentages 

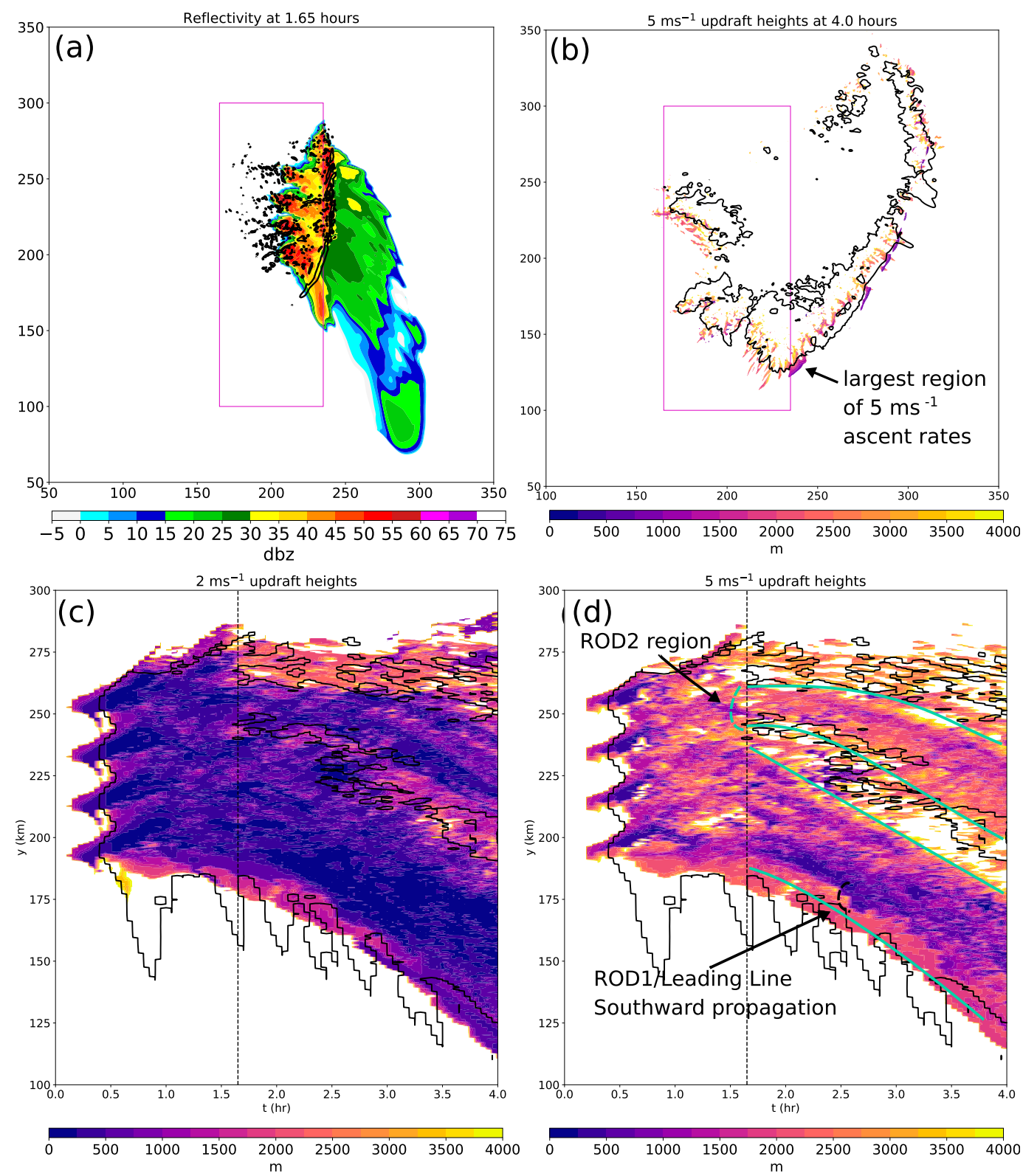

FIG. 17. (a) Reflectivity (shading) and $0.5-\mathrm{km} w=1 \mathrm{~m} \mathrm{~s}^{-1}$ (black contours) at a time shortly before the southwestern edge of the leading line gained a stronger southerly component of motion. (b) The minimum height (m) where $5 \mathrm{~m} \mathrm{~s}^{-1}$ updrafts are observed (shading) and 40-dBZ reflectivity (black contours). (c) A longitude-time diagram of the minimum in the $x$ direction of the column minimum height of $2 \mathrm{~m} \mathrm{~s}^{-1}$ updrafts in the box bounded by the magenta lines. Values in the $y$ direction $(\mathrm{km})$ are plotted as a function of time (h). (d) As in (c), but for $5 \mathrm{~m} \mathrm{~s}^{-1}$ updrafts. Black contours highlight locations where reflectivity greater than $40 \mathrm{dBZ}$ was observed somewhere in the bounded $x$ direction. The first dashed line in (c) and (d) marks the time of (a).

exceed $25 \%$. This along with the previous analysis indicates that updrafts along the leading line become more surface based with time; vertical velocities are observed closer to the surface along the southern outflow boundary as it takes on a more southward motion, and more near-surface tracer is lofted by the leading line over time. This fits with the findings of Parker (2008),
French and Parker (2008), and Billings and Parker (2012) and other recent works that suggest that even in strongly stable environments, some portion of the convective inflow still draws from the near-surface environment. Furthermore, it agrees with findings of Parker et al. (2020) that suggest that nocturnal convection can evolve from more elevated to more surface based over time. 

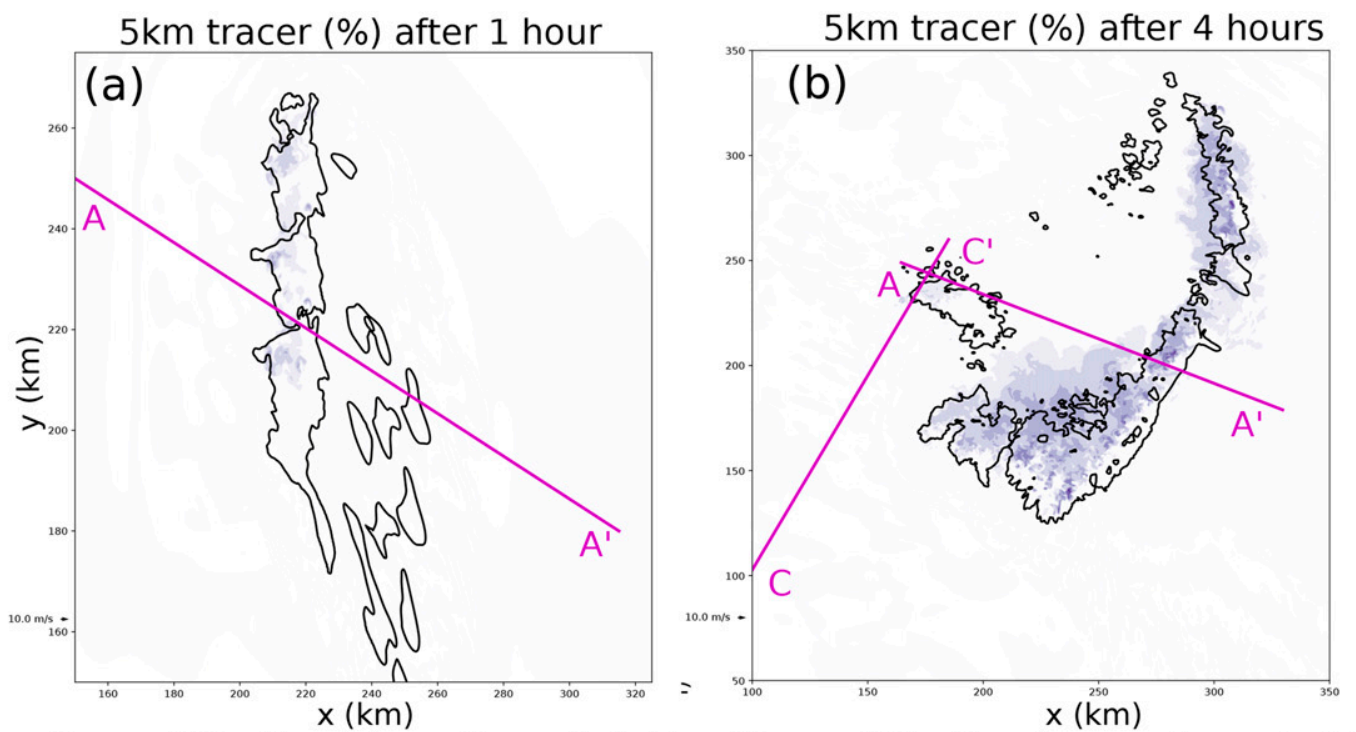

Tracer (\%) after 1 hour through A-A'

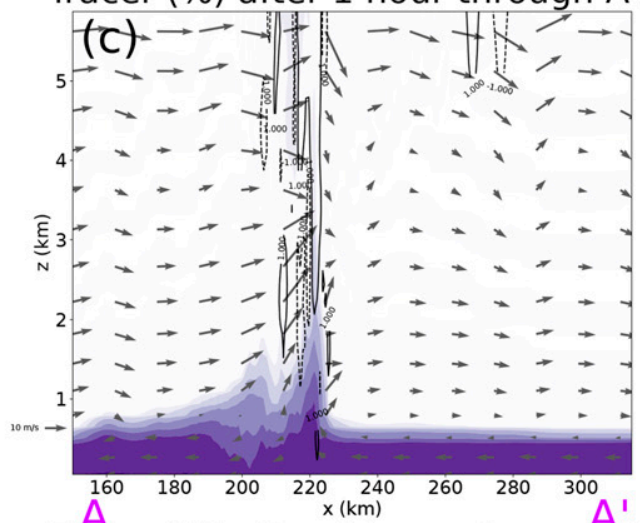

Tracer (\%) after 4 hours through A-A

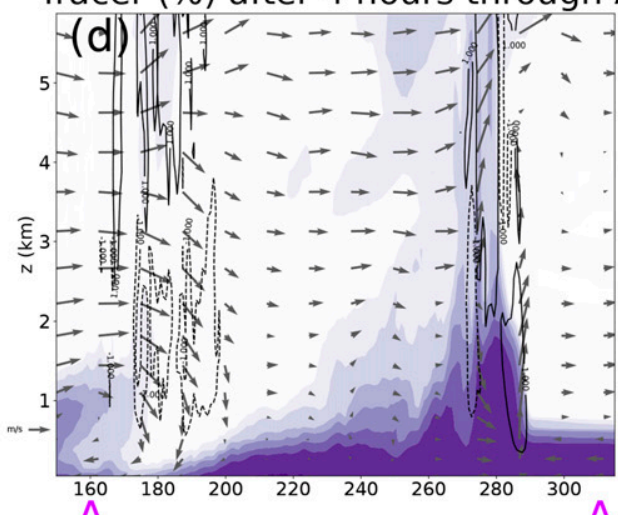

Tracer (\%) after 2 hours through A-A'
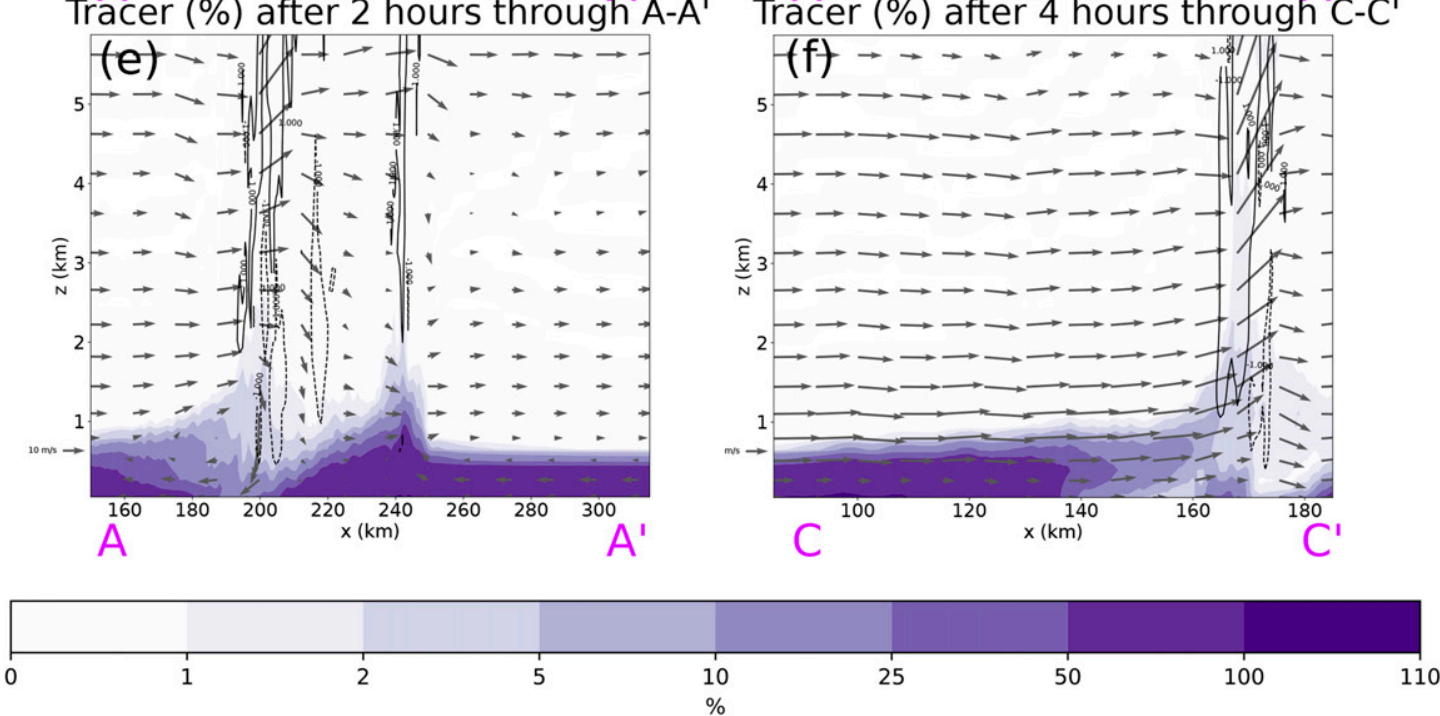

FIG. 18. Percentage of initial concentration of parcel tracer released below $500 \mathrm{~m}$ at initialization: (a) percent at $5 \mathrm{~km}$ after $1 \mathrm{~h},(\mathrm{~b})$ percent at $5 \mathrm{~km}$ after $4 \mathrm{~h}$, and cross sections through (c) $\mathrm{A}-\mathrm{A}^{\prime}$ after $1 \mathrm{~h}$, (d) $\mathrm{A}-\mathrm{A}^{\prime}$ after $4 \mathrm{~h}$, (e) $\mathrm{A}-\mathrm{A}^{\prime}$ after $2 \mathrm{~h}$, and (f) $\mathrm{C}-\mathrm{C}^{\prime}$ after $4 \mathrm{~h}$. Black contours in (a) and (b) indicate lowest level reflectivity $>40 \mathrm{dBZ}$, and open gray contours represent $1 \mathrm{~m} \mathrm{~s}^{-1}$ updrafts. Black contours in (c)-(f) represent $\pm 1 \mathrm{~m} \mathrm{~s}^{-1}$ updrafts. Note that color shading is not linear. Cross sections are averaged over a width of $3 \mathrm{~km}$. 
Passive tracer amounts greater than $25 \%$ cover a broader region at $5 \mathrm{~km}$ in the southern portions of the MCS than in the northern portions of the MCS. This suggests, that even in this environment with horizontally homogeneous initial conditions, in addition to differences in updraft base height, there is some heterogeneity in the strength of low-level updrafts. In other words, the interaction of the convection with the stable layer is likely not the same everywhere within an MCS, even along the same outflow boundary. These differences may be tied to the strength of convective downdrafts and the character of the outflow. In most of the ROD2 region, fewer than $5 \%$ of parcels make it to $5 \mathrm{~km}$, indicating that convection in this region is nearly completely elevated (Fig. 18f). Earlier trajectory analysis indicated that when stable layer parcels were lofted by ROD updrafts in this region, they had first interacted with the leading line in some fashion. A comparison of a cross section through ROD and leading line updrafts emphasizes that more near-surface tracers are lofted by the leading line, while $<2 \%$ of near-surface tracers even make it above 3-km ROD cross section (Fig. 18d). This combined with Figs. $17 \mathrm{~b}$ and $17 \mathrm{~d}$, suggests that $5 \mathrm{~m} \mathrm{~s}^{-1}$ updrafts in the region of ROD are more elevated than updrafts along the leading line. In fact, Figs. 18 and 17d argue that at least the southern and eastern portions of the leading line are still closely linked to the air near the surface. The idea that the forward-propagating portion of the MCS is more effective at lifting near-surface parcels than other parts of the MCS is consistent with findings of Schumacher (2015) where back-building regions of the simulated MCS ingested less near-surface air than the forward propagating portion of the MCS.

\section{Summary and conclusions}

In this work, a sounding launched as part of the PECAN field campaign on the 24-25 June 2015 was used as the environment in an idealized simulation with horizontally homogeneous initial conditions. This simulation was unique for a few reasons: 1) The initial environment had a very strong low-level stable layer, different from previous studies focused on understanding ROD, 2) The simulation produced an intrusion instead of a traditional surface cold pool, and its interactions with the vertical wind shear can be used to explain many aspects of the simulation. 3) The simulated MCS was complex, three-dimensional, and resembled the observed MCS even though the initial conditions were horizontally homogeneous. While some studies have focused on the spatial heterogeneity of the background environment (baroclinic zone, LLJ exit region, etc.) as important for the initiation and upscale growth of MCSs (e.g., Trier et al. 2020; Augustine and Caracena 1994; Tuttle and Davis 2006; Trier et al. 2006) and in the development of ROD (Keene and Schumacher 2013) this simulation has no external forcing for ascent in the background environment. Though external forcing likely played a role in the development of convection observed on the day of the environmental sounding, the homogeneous idealized setting provides an opportunity to explore other processes that might also support MCS development and ROD.

A summary of the major findings are as follows:

- The greatest observed $\theta$ deficits are above the surface, similar to the 25 June 2015 case that motivated this study and several other PECAN cases discussed in Hitchcock et al. (2019).

- Despite the strong stable layer, downdrafts still reach the surface, but their effect is a warm perturbation that could be due to a variety of possible reasons. This may not necessarily manifest as strongly in heterogeneous simulations or in the real environment where other processes act simultaneously to cool the surface.

- Different mechanisms support different regions of the MCS. This influences the relevant inflow layer.

- Downdraft air that is potentially warmer than the near-surface air may reach a layer of similar density and then spread out as an intrusion.

- The vertical wind profile acts to modify the structure of the intrusion and the amplitude of wavelike perturbations. Application of RKW theory and concepts from Schmidt and Cotton (1990) in relevant layers can help to explain these modifications.

- ROD is likely supported by the upper half of an intrusion (e.g., elevated cold pool) amplified by favorable vertical wind shear in the same layer.

- Since parcels return nearly to their original heights prior to being lifted in ROD updrafts, the bore associated with leading southwest convective line does not play an important role in this case.

- Even in an environment with the strongest observed stability during the PECAN field campaign, at least some portion of the convection became surface based, with $5 \mathrm{~m} \mathrm{~s}^{-1}$ updrafts observed below $500 \mathrm{~m}$ and parcels originating at $50 \mathrm{~m}$ lofted by updrafts. This further supports the growing body of evidence that nocturnal storms may not actually be decoupled from the stable boundary layer.

Even in an idealized environment, it is clear that the interaction of an MCS with a strong low-level stable layer in a sheared environment is complex. The coldest rain-cooled air in some MCSs may exist above the surface, and propagate as a density-current intrusion that interacts with the vertical wind shear. In this case, ROD is likely supported by an amplified intrusion, that is 
likely reinforced by the convective updrafts which enhance cooling below them. There is still clearly much more work to be done to understand all of the relevant processes. Future work will expand on results discussed here and focus on trying to unravel the interaction between convective outflow, vertical wind shear, gravity waves, and what exactly about the wind shear profile makes MCS and ROD development possible.

Acknowledgments. This research is supported by NSF Grants AGS-1359727 and AGS-1636663.Thanks to Matt Parker for providing some of the early motivation for this work, for his review, and resulting discussions. We appreciate our editor Stan Trier, and thank him for his patience, advice, and helpful constructive feedback. Thanks also to Mitch Moncrieff and an anonymous reviewer who provided additional constructive insights that helped improve this manuscript. Thanks to Todd Lane, the ARC Centre of Excellence for Climate Extremes (CE170100023), and the University of Melbourne for their support during the submission and review process. A NOAA/Office of Atmospheric Research (OAR)/Office of Weather and Air Quality (AWAQ) award provided all mobile sounding expendables used by the CSU and two NSSL sounding vehicles during PECAN. Thanks to Sean Waugh and NOAA/National Severe Storms Laboratory (NSSL) for configuring and maintaining the CSU and two NSSL mobile sounding vehicles. Thanks to Kevin Haghi for helpful discussions on stability and wave dynamics, and Rich Rotunno for helping us to improve our conceptual model of intrusions in vertical wind shear. Thanks to committee members Susan van den Heever, David Randall, and Richard Eykholt for feedback at various stages of this work. Thanks to members of the Schumacher research group past and present (especially Erik Nielsen and Greg Herman), Leah Grant, Peter Marinescu, Manda Chasteen, and those who have given feedback at various conferences and seminars. Thanks to James Goldie for his suggestions on how to make the 3D visualization in Fig. 15 easier to interpret. A special thank you also goes to the many PECAN participants for their dedication to seeing the sunrise before bedtime. We would like to acknowledge high-performance computing support from Cheyenne (doi:10.5065/D6RX99HX) provided by NCAR's Computational and Information Systems Laboratory, sponsored by the National Science Foundation.

Data availability statement. The CM1 model (Bryan and Fritsch 2002) used in these simulations is freely available online at https://www2.mmm.ucar.edu/people/ bryan/cm $1 /$. The radiosonde data from the PECAN field campaign used (Ziegler et al. 2016) are available on the NCAR EOL webpage under Data Access.

\section{REFERENCES}

Augustine, J. A., and F. Caracena, 1994: Lower-tropospheric precursors to nocturnal MCS development over the central United States. Wea. Forecasting, 9, 116-135, https://doi.org/ 10.1175/1520-0434(1994)009<0116:LTPTNM > 2.0.CO;2.

Billings, J. M., and M. D. Parker, 2012: Evolution and maintenance of the 22-23 June 2003 nocturnal convection during BAMEX. Wea. Forecasting, 27, 279-300, https://doi.org/10.1175/WAFD-11-00056.1.

Blake, B. T., D. B. Parsons, K. R. Haghi, and S. G. Castleberry, 2017: The structure, evolution, and dynamics of a nocturnal convective system simulated using the WRF-ARW model. Mon. Wea. Rev., 145, 3179-3201, https://doi.org/10.1175/MWR-D-16-0360.1.

Bluestein, H. B., Z. B. Wienhoff, D. D. Turner, D. W. Reif, J. C. Snyder, K. J. Thiem, and J. B. Houser, 2017: A comparison of the finescale structures of a prefrontal wind-shift line and a strong cold front in the southern plains of the United States. Mon. Wea. Rev., 145, 3307-3330, https://doi.org/ 10.1175/MWR-D-16-0403.1.

Bryan, G. H., and J. M. Fritsch, 2002: A benchmark simulation for moist nonhydrostatic numerical models. Mon. Wea. Rev., 130, 2917-2928, https://doi.org/10.1175/1520-0493(2002)130<2917: ABSFMN $>2.0 . \mathrm{CO} ; 2$.

Chappell, C. F., 1986: Quasi-stationary convective events. Mesoscale Meteorology and Forecasting, P. S. Ray, Ed., Amer. Meteor. Soc., 289-309, https://doi.org/10.1007/978-1-935704-20-113.

Chasteen, M. B., S. E. Koch, and D. B. Parsons, 2019: Multiscale processes enabling the longevity and daytime persistence of a nocturnal mesoscale convective system. Mon. Wea. Rev., 147, 733-761, https://doi.org/10.1175/MWR-D-18-0233.1.

Coffer, B. E., and M. D. Parker, 2015: Impacts of increasing low-level shear on supercells during the early evening transition. Mon. Wea. Rev., 143, 1945-1969, https://doi.org/10.1175/MWR-D-1400328.1.

Corfidi, S. F., 2003: Cold pools and MCS propagation: Forecasting the motion of downwind-developing MCSs. Wea. Forecasting, 18, 997-1017, https://doi.org/10.1175/1520-0434(2003)018<0997: CPAMPF $>2.0 . \mathrm{CO} ; 2$.

—, J. H. Merritt, and J. M. Fritsch, 1996: Predicting the movement of mesoscale convective complexes. Wea. Forecasting, 11, 41-46, https://doi.org/10.1175/1520-0434(1996)011<0041: PTMOMC $>2.0 . C O ; 2$.

Crook, N. A., and M. W. Moncrieff, 1988: The effect of large-scale convergence on the generation and maintenance of deep moist convection. J. Atmos. Sci., 45, 3606-3624, https://doi.org/ 10.1175/1520-0469(1988)045<3606:TEOLSC $>2.0$. CO 2 .

Davis, C., and Coauthors, 2004: The Bow Echo and MCV experiment: Observations and opportunities. Bull. Amer. Meteor. Soc., 85, 1075-1093, https://doi.org/10.1175/BAMS-85-8-1075.

Deardorff, J. W., 1980: Stratocumulus-capped mixed layers derived from a three-dimensional model. Bound.-Layer Meteor., 18, 495-527, https://doi.org/10.1007/BF00119502.

Doswell, C. A., III, H. E. Brooks, and R. A. Maddox, 1996: Flash flood forecasting: An ingredients-based methodology. Wea. Forecasting, 11, 560-581, https://doi.org/10.1175/1520-0434(1996) $011<0560$ :FFFAIB $>2.0 . \mathrm{CO} ; 2$.

Durran, D. R., and J. B. Klemp, 1983: A compressible model for the simulation of moist mountain waves. Mon. Wea. Rev., 111, 
2341-2361, https://doi.org/10.1175/1520-0493(1983)111<2341: ACMFTS $>2.0 . C O ; 2$.

Flynn, M. R., and B. R. Sutherland, 2004: Intrusive gravity currents and internal gravity wave generation in stratified fluid. J. Fluid Mech., 514, 355-383, https://doi.org/10.1017/S0022112004000400.

— , and P. Linden, 2006: Intrusive gravity currents. J. Fluid Mech., 568, 193-202, https://doi.org/10.1017/S0022112006002734.

French, A. J., and M. D. Parker, 2008: The initiation and evolution of multiple modes of convection within a meso-alphascale region. Wea. Forecasting, 23, 1221-1252, https://doi.org/ 10.1175/2008WAF2222136.1.

$\longrightarrow$, and —, 2010: The response of simulated nocturnal convective systems to a developing low-level jet. J. Atmos. Sci., 67, 3384-3408, https://doi.org/10.1175/2010JAS3329.1.

Fritsch, J. M., and G. S. Forbes, 2001: Mesoscale convective systems. Severe Convective Storms, Meteor. Monogr., No. 50, Amer. Meteor. Soc., 323-357.

Geerts, B., and Coauthors, 2017: The 2015 Plains Elevated Convection At Night field project. Bull. Amer. Meteor. Soc., 98, 767-786, https://doi.org/10.1175/BAMS-D-15-00257.1.

Grasmick, C., B. Geerts, D. D. Turner, Z. Wang, and T. Weckwerth, 2018: The relation between nocturnal MCS evolution and its outflow boundaries in the stable boundary layer: An observational study of the 15 July 2015 MCS in PECAN. Mon. Wea. Rev., 146, 3203-3226, https://doi.org/10.1175/MWR-D-18-0169.1.

Haertel, P. T., R. H. Johnson, and S. N. Tulich, 2001: Some simple simulations of thunderstorm outflows. J. Atmos. Sci., 58, 504-516, https://doi.org/10.1175/1520-0469(2001) $058<0504:$ SSSOTO $>2.0$.CO;2.

Haghi, K. R., D. B. Parsons, and A. Shapiro, 2017: Bores observed during IHOP_2002: The relationship of bores to the nocturnal environment. Mon. Wea. Rev., 145, 3929-3946, https://doi.org/ 10.1175/MWR-D-16-0415.1.

—, and Coauthors, 2019: Bore-ing into nocturnal convection. Bull. Amer. Meteor. Soc., 100, 1103-1121, https://doi.org/ 10.1175/BAMS-D-17-0250.1.

Hitchcock, S. M., R. S. Schumacher, G. R. Herman, M. C. Coniglio, M. D. Parker, and C. L. Ziegler, 2019: Evolution of pre- and postconvective environmental profiles from mesoscale convective systems during PECAN. Mon. Wea. Rev., 147, 23292354, https://doi.org/10.1175/MWR-D-18-0231.1.

Johnson, R. H., and P. J. Hamilton, 1988: The relationship of surface pressure features to the precipitation and airflow structure of an intense midlatitude squall line. Mon. Wea. Rev., 116, 1444-1473, https://doi.org/10.1175/1520-0493(1988)116<1444: TROSPF $>2.0 . \mathrm{CO} ; 2$.

Keene, K. M., and R. S. Schumacher, 2013: The bow and arrow mesoscale convective structure. Mon. Wea. Rev., 141, 16481672, https://doi.org/10.1175/MWR-D-12-00172.1.

Klemp, J. B., and R. B. Wilhelmson, 1978: The simulation of threedimensional convective storm dynamics. J. Atmos. Sci., 35, 1070-1096, https://doi.org/10.1175/1520-0469(1978)035<1070: TSOTDC $>2.0 . \mathrm{CO} ; 2$.

—, R. Rotunno, and W. C. Skamarock, 1994: On the dynamics of gravity currents in a channel. J. Fluid Mech., 269, 169-198, https://doi.org/10.1017/S0022112094001527.

Liu, C., and M. W. Moncrieff, 1996: A numerical study of the effects of ambient flow and shear on density currents. Mon. Wea. Rev., 124, 2282-2303, https://doi.org/10.1175/1520-0493(1996) 124<2282:ANSOTE $>2.0$.CO;2.

, and - 2017: Shear-parallel mesoscale convective systems in a moist low-inhibition mei-yu front environment. J. Atmos. Sci., 74, 4213-4228, https://doi.org/10.1175/JAS-D-17-0121.1.
Loftus, A. M., D. B. Weber, and C. A. Doswell III, 2008: Parameterized mesoscale forcing mechanisms for initiating numerically simulated isolated multicellular convection. Mon. Wea. Rev., 136, 2408-2421, https://doi.org/10.1175/ 2007MWR2133.1.

Loveless, D. M., T. J. Wagner, D. D. Turner, S. A. Ackerman, and W. F. Feltz, 2019: A composite perspective on bore passages during the PECAN campaign. Mon. Wea. Rev., 147, 13951413, https://doi.org/10.1175/MWR-D-18-0291.1.

Maddox, R. A., 1980: Mesoscale convective complexes. Bull. Amer. Meteor. Soc., 61, 1374-1387, https://doi.org/10.1175/ 1520-0477(1980)061<1374:MCC > 2.0.CO;2.

_ C. F. Chappell, and L. R. Hoxit, 1979: Synoptic and meso$\alpha$-scale aspects of flash flood events. Bull. Amer. Meteor. Soc. 60, 115-123, https://doi.org/10.1175/1520-0477-60.2.115.

Marsham, J. H., K. A. Browning, J. C. Nicol, D. J. Parker, E. G. Norton, A. M. Blyth, U. Corsmeier, and F. M. Perry, 2010: Multi-sensor observations of a wave beneath an impacting rear-inflow jet in an elevated mesoscale convective system. Quart. J. Roy. Meteor. Soc., 136, 1788-1812, https://doi.org/ 10.1002/qj.669.

Moncrieff, M. W., 1992: Organized convective systems: Archetypal dynamical models, mass and momentum flux theory, and parameterization. Quart. J. Roy. Meteor. Soc., 118, 819-850, https://doi.org/10.1002/qj.49711850703.

Morrison, H., J. A. Curry, and V. I. Khvorostyanov, 2005: A new double-moment microphysics parameterization for application in cloud and climate models. Part I: Description. J. Atmos. Sci., 62, 1665-1677, https://doi.org/10.1175/JAS3446.1.

Parker, M. D., 2008: Response of simulated squall lines to low-level cooling. J. Atmos. Sci., 65, 1323-1341, https://doi.org/10.1175/ 2007JAS2507.1.

— 2 2014: Composite VORTEX2 supercell environments from near-storm soundings. Mon. Wea. Rev., 142, 508-529, https:// doi.org/10.1175/MWR-D-13-00167.1.

- B. S. Borchardt, R. L. Miller, and C. L. Ziegler, 2020: Simulated evolution and severe wind production by the 25 26 June 2015 nocturnal MCS from PECAN. Mon. Wea. Rev., 148, 183-209, https://doi.org/10.1175/MWR-D-19-0072.1.

Parsons, D. B., K. R. Haghi, K. T. Halbert, B. Elmer, and J. Wang, 2019: The potential role of atmospheric bores and gravity waves in the initiation and maintenance of nocturnal convection over the Southern Great Plains. J. Atmos. Sci., 76, 43-68, https://doi.org/10.1175/JAS-D-17-0172.1.

Peters, J. M., and R. S. Schumacher, 2014: Objective categorization of heavy-rain-producing MCS synoptic types by rotated principal component analysis. Mon. Wea. Rev., 142, 1716-1737, https://doi.org/10.1175/MWR-D-13-00295.1.

— training in a flash-flood-producing mesoscale convective system. Mon. Wea. Rev., 143, 1058-1085, https://doi.org/10.1175/ MWR-D-14-00070.1.

$\longrightarrow$, and - 2015b: The simulated structure and evolution of a quasi-idealized warm season convective system with a training convective line. J. Atmos. Sci., 72, 1987-2010, https://doi.org/ 10.1175/JAS-D-14-0215.1.

— and - 2016: Dynamics governing a simulated mesoscale convective system with a training convective line. J. Atmos. Sci., 73, 2643-2664, https://doi.org/10.1175/JAS-D-15-0199.1.

Physick, W., W. Downey, A. Troup, B. Ryan, and P. Meighen, 1985: Mesoscale observations of a prefrontal squall line. Mon. Wea. Rev., 113, 1958-1969, https://doi.org/10.1175/1520-0493(1985) 113<1958:MOOAPS > 2.0.CO;2. 
Raymond, D. J., and R. Rotunno, 1989: Response of a stably stratified flow to cooling. J. Atmos. Sci., 46, 2830-2837, https://doi.org/ 10.1175/1520-0469(1989)046<2830:ROASSF > 2.0.CO;2.

Rottman, J. W., and J. E. Simpson, 1989: The formation of internal bores in the atmosphere: A laboratory model. Quart. J. Roy. Meteor. Soc., 115, 941-963, https://doi.org/10.1002/qj.49711548809.

Rotunno, R., J. B. Klemp, and M. L. Weisman, 1988: A theory for strong, long-lived squall lines. J. Atmos. Sci., 45, 463-485, https:// doi.org/10.1175/1520-0469(1988)045<0463:ATFSLL>2.0.CO;2.

Schmidt, J. M., and W. R. Cotton, 1990: Interactions between upper and lower tropospheric gravity waves on squall line structure and maintenance. J. Atmos. Sci., 47, 1205-1222, https://doi.org/ 10.1175/1520-0469(1990)047<1205:IBUALT>2.0.CO;2.

Schumacher, R. S., 2009: Mechanisms for quasi-stationary behavior in simulated heavy-rain-producing convective systems. J. Atmos. Sci., 66, 1543-1568, https://doi.org/10.1175/2008JAS2856.1.

- , 2015: Sensitivity of precipitation accumulation in elevated convective systems to small changes in low-level moisture. J. Atmos. Sci., 72, 2507-2524, https://doi.org/10.1175/JAS-D14-0389.1.

__ 2017: Heavy rainfall and flash flooding. Natural Hazard Science, Oxford Research Encyclopedias, https://doi.org/ 10.1093/ACREFORE/9780199389407.013.132.

_ , and R. H. Johnson, 2005: Organization and environmental properties of extreme-rain-producing mesoscale convective systems. Mon. Wea. Rev., 133, 961-976, https://doi.org/10.1175/ MWR2899.1.

_ rainfall in a midlatitude warm-season flash flood. Mon. Wea. Rev., 136, 3964-3986, https://doi.org/10.1175/2008MWR2471.1.

_ convective systems associated with midlevel cyclonic circulations. Wea. Forecasting, 24, 555-574, https://doi.org/10.1175/ 2008WAF2222173.1.

Sutherland, B. R., and J. R. Munroe, 2014: Intrusions in stratified fluids. University of Alberta, Edmonton, Alberta, Canada, 6 pp., http://citeseerx.ist.psu.edu/viewdoc/download?doi=10.1.1.532. $9065 \&$ rep $=$ rep $1 \&$ type $=$ pdf.
_ P. J. Kyba, and M. R. Flynn, 2004: Intrusive gravity currents in two-layer fluids. J. Fluid Mech., 514, 327-353, https:// doi.org/10.1017/S0022112004000394.

Trier, S. B., and D. B. Parsons, 1993: Evolution of environmental conditions preceding the development of a nocturnal mesoscale convective complex. Mon. Wea. Rev., 121, 1078-1098, https://doi.org/10.1175/1520-0493(1993)121<1078:EOECPT> 2.0.CO;2.

— C. A. Davis, D. A. Ahijevych, M. L. Weisman, and G. H. Bryan, 2006: Mechanisms supporting long-lived episodes of propagating nocturnal convection within a 7-day WRF model simulation. J. Atmos. Sci., 63, 2437-2461, https://doi.org/10.1175/JAS3768.1.

_ S. D. Kehler, and J. Hanesiak, 2020: Observations and simulation of elevated nocturnal convection initiation on 24 June 2015 during PECAN. Mon. Wea. Rev., 148, 613-635, https:// doi.org/10.1175/MWR-D-19-0218.1.

Tuttle, J. D., and C. A. Davis, 2006: Corridors of warm season precipitation in the central United States. Mon. Wea. Rev., 134, 2297-2317, https://doi.org/10.1175/MWR3188.1.

Ungarish, M., 2005: Intrusive gravity currents in a stratified ambient: Shallow-water theory and numerical results. J. Fluid Mech., 535, 287-323, https://doi.org/10.1017/S0022112005004854.

—, 2009: An Introduction to Gravity Currents and Intrusions. Chapman and Hall/CRC, 489 pp.

Weisman, M. L., and R. Rotunno, 2004: "A theory for strong longlived squall lines" revisited. J. Atmos. Sci., 61, 361-382, https:// doi.org/10.1175/1520-0469(2004)061<0361:ATFSLS >2.0.CO;2.

Xu, Q., 1992: Density currents in shear flows-A two-fluid model. J. Atmos. Sci., 49, 511-524, https://doi.org/10.1175/15200469(1992)049<0511:DCISFA > 2.0.CO;2.

Xue, M., Q. Xu, and K. K. Droegemeier, 1997: A theoretical and numerical study of density currents in nonconstant shear flows. J. Atmos. Sci., 54, 1998-2019, https://doi.org/10.1175/15200469(1997)054<1998:ATANSO>2.0.CO;2.

Ziegler, C. L., M. C. Coniglio, M. D. Parker, and R. S. Schumacher, 2016: CSU/NCSU/NSSL MGAUS radiosonde data, version 3.0. UCAR/NCAR-Earth Observing Laboratory, accessed 22 September 2016, https://doi.org/10.5065/D6W66HXN. 